\title{
HISTOIRE DE QUELQUES MIROIRS DÉFORMANTS ORIENT-OCCIDENT
}

\author{
LE CODE DE LA NATURE, POËME DE CONFUCIUS \\ TRADUIT ET COMMENTÉ PAR LE P. PARENNIN \\ PARIS, LEROY, 1788, IN-8 ${ }^{\circ}, 127$ PAGES
}

Isabelle LANDRY-DERON

\begin{abstract}
RÉSUMÉ : L'article exhume une supercherie littéraire empruntant au goût chinois publiée à Paris en 1788 et tente d'en décortiquer les implications intellectuelles. Le faux porte sur le détournement du titre de l'ouvrage - référence au pamphlet de Morelly, alors communément attribué à Diderot -, de l'auteur - Confucius, philosophe contemporain de Socrate qui n'a laissé aucun ouvrage de sa main -, du travail de traduction - qui par définition n'a jamais pu exister - et de commentaire - attribué à un jésuite de la mission française en Chine. Le véritable auteur du faux, Louis Lavicomterie, Montagnard et régicide, l'a revendiqué pendant la Révolution. La reconstitution des circonstances et des arrière-plans historiques du texte tente de circonscrire la charge émotive et pamphlétaire de ce message chinois falsifié pour véhiculer un plaidoyer en faveur de l'abolition de la peine de mort et une satire de la justice et du clergé. Derrière Confucius, Lavicomterie a inscrit Voltaire en filigrane. On peut y lire autant de miroirs des attentes à la veille de la Révolution : la recherche d'une morale laïque permettant de dépasser les discordes religieuses et le rejet du droit divin, fondement de l'Ancien Régime.
\end{abstract}

MoTS-CLÉS : faux, supercheries littéraires, Jésuites, missions, Chine, XVIII ${ }^{\mathrm{e}}$ siècle.

ABSTRACT : The paper brings to light a literary fabrication cast as a «chinoiserie » published in Paris in 1788 and tentatively explores its implicit message. The fabrication implies the title - allusion to the pamphlet written by the radical Morelly then commonly credited to Diderot -, the author - the Chinese philosopher contemporary of Socrates -, the alleged translation - which could never have occurred -, and the commentary attributed to a Jesuit of the French mission in China. The genuine author of the fabrication, a plea for the abolishion of the death penalty and a satire on the legal institution and the Clergy, is Louis Lavicomterie who later will be a member of the Montagne and will vote the death of Louis XVI. He fathered the book during the French Revolution. The reconstitution of the historical context helps to decipher the cryptic purpose of this chinese message. Behind Confucius, Lavicomterie has introduced Voltaire. The text reflects the moral and intellectual expectations at the eve of the turmoil : the increasing search for secularization and the rejection of the fundamental divine rights of the Ancien Régime.

KEYWORDS : literary fabrication, Jesuit, missions, China, XVIII ${ }^{\text {th }}$ century. 
ZUSAMMENFASSUNG : In dem Artikel wird eine literarische Fälschung vorgestellt, die 1788 in Paris erschienen und aus der damaligen China-Mode hervorgegangen ist. Die Fälschung bezieht sicht auf den Titel des Werkes (Anspielung auf ein Pamphlet von Morelly, das damals allgemein Diderot zugeschrieben wurde, auf den Verfasser (den Philosophen Konfuzius, einen Zeitgenossen von Sokrates, der kein eigenes Werk hinterlassen hat), auf die Übersetzung (die es definitionsgemäß nie geben konnte) und auf den Kommentar, der einem Jesuiten der französischen China-Mission zugeschrieben wird. Der wahre Verfasser der Fälschung, Louis Lavicomterie, Königsmörder und Mitglied der Bergpartei im Nationalkonvent, hat sich während der Revolution dazu bekannt. Bei der Rekonstruktion der Umstände und der historischen Hintergründe des Textes wird versucht, die emotionsgeladene und reißerische Aussage dieser falschen chinesischen Botschaft zu beschreiben, die für die Abschaffung der Todesstrafe eintrat und eine Satire auf Justiz und Klerus darstellte. Hinter Konfuzius hat Lavicomterie Voltaire versteckt. Der Text spiegelt alle Erwartungen wider, die mit der Revolution verknüpft wurden : die Suche nach einer laizistischen Moral, die eine Überwindung der religiösen Spaltung ermöglichen sollte, und die Ablehnung der von Gott gegebenen Rechtsordnung, die die Grundlage des Ancien Régime war.

STICHWÖRTER : Literarische Fälschung, Jesuiten, Mission, China, 18. Jahrhundert.

Isabelle LANDRY-DERON, née en 1952, a soutenu en sinologie une thèse sur la Description de la Chine du père Du Halde (1735), dont la version remaniée vient d'être publiée par les Éditions de l'École des hautes études en sciences sociales sous le titre La Preuve par la Chine. Son domaine de recherche est l'activité de la mission jésuite française en Chine aux $\mathrm{XVII}^{\mathrm{e}}$ et XVIII ${ }^{\mathrm{e}}$ siècles.

Adresse : EHESS, Centre d'études sur la Chine moderne et contemporaine, 54 boulevard Raspail, F-75006 Paris.

Courrier électronique : ideron@wanadoo.fr 
En 1788, le libraire Leroy, situé rue Saint-Jacques « vis-à-vis la Parcheminerie » dans le carré du Quartier latin de Paris qui abritait nombre de boutiques de livres, mit en vente un ouvrage de petit format (in- $8^{\circ}$ ), prétendument imprimé à Londres, annonçant un " poème de Confucius », intitulé Le Code de la nature, traduit et commenté par un jésuite de la mission française en Chine, le père Dominique Parrenin ${ }^{1}$, mort depuis plus de quarante ans.

Lorsque le lecteur ouvrait cet opuscule de cent vingt-sept pages, la contemplation de la gravure de garde, sous-titrée d'un vers extrait du poème, « $\mathrm{Ne}$ peut-on sans la mort punir les criminels », représentant dans le décor d'une geôle des condamnés chargés de chaînes implorant deux figures féminines au sein dénudé symbolisant la Justice et la Nature, ne pouvait que l'intriguer sur la finalité de cet exercice poétique.

Confucius, philosophe chinois $\mathrm{du} \mathrm{vI}^{\mathrm{e}}$ siècle avant J.-C., avait-il vraiment écrit un poème portant le même titre qu'un pamphlet politique hardi attribué à Diderot, âme de l'Encyclopédie ? Un membre de la compagnie de Jésus avait-il vraiment pris la peine, à l'insu de ses confrères, de traduire et commenter ce brûlot jusqu'alors inédit ? Par quels chemins mystérieux un tel texte aurait-il pu parvenir en Europe ? Qui aurait eu, quinze ans après la suppression de cet institut religieux, intérêt à le publier ?

En fait, le lecteur tenait en main l'une des plus étranges supercheries littéraires du XVIII ${ }^{\mathrm{e}}$ siècle. Pendant la Révolution, son auteur l'a revendiquée : Louis Lavicomterie $^{2}$. L'ironie de l'Histoire muera cet opposant à la peine capitale, moins de quatre ans après la publication de son pamphlet, en régicide. Député de Paris à la Convention, Lavicomterie se prononça pour la peine de mort de Louis XVI sans condition.

1. L'intéressé signait son nom en suivant cette orthographe mais même de son vivant des variantes sont apparues dans plusieurs publications. L'orthographe retenue par Lavicomterie (Parennin) reprend celle adoptée par Voltaire.

2. Paternité revendiquée dans Les Droits du peuple sur l'Assemblée nationale, ouvrage que Lavicomterie fit paraître en 1791, LAVICOMTERIE, 1791a, p. 101, n. 1. L'information est reproduite dans la Notice sur Lavicomterie et ses ouvrages, placée en tête de la réédition de 1834 de deux autres ouvrages de Lavicomterie, Les Crimes des rois de France, p. VIII, n. 1 et $\mathrm{Du}$ peuple et des rois, p. II, n. 1. Le faux est listé par QuÉRARD, 1964, vol. I, p. 774. WELlER, 1970, vol. II, p. 235 confirme que l'adresse de Londres est fausse. Le livre aurait été imprimé à Paris. SOMMERvogel et DE BACKER, 1890-1932, vol. VI, col. 290, signalent la supercherie : «L'auteur de cet ouvrage dirigé contre la religion, est de la Vicomterie ou Coqueley de Chaussepierre ; il s'est caché sous le nom du P. Parrenin pour se faire lire. » Cependant PFISTER, 1932-1934, ici 1934, notice 233, art. 6, p. 514, s'est laissé abuser et inclut le texte dans la bibliographie de Parrenin. Signalons que le P. Pfister (1833-1891), historiographe des missionnaires jésuites de Chine, a toujours travaillé en Chine et qu'il est fort probable qu'il ne vit pas lui-même le pamphlet. 
Un philosophe chinois contemporain de Socrate, un appel généreux à une nature parée d'atours libérateurs, un jésuite encore célèbre des années après sa mort et la proscription de la compagnie de Jésus en France en 1762 : autant d'ingrédients d'une curieuse énigme à la veille d'un grand bouleversement. Reprenons-en les fils en tâchant de reconstituer les impressions qui purent décider ceux qui poussèrent la porte de l'échoppe de Leroy à débourser quelques sols pour ce pastiche.

\section{L'AUTEUR PRÉSUMÉ}

À la fin du XVIII siècle, Confucius (v. 551-v. 479 av. J.-C.), le maître dont l'enseignement a si durablement structuré la pensée chinoise, promu pour la circonstance poète en alexandrins, était loin d'être un inconnu en Europe. Il était même un personnage, incarnant des perceptions extrêmement complexes.

En 1687, des jésuites sinisants avaient fait imprimer à Paris une traduction en latin des extraits des principales compilations rassemblées par ses disciples. Cet ouvrage, le Confucius sinarum philosophus ${ }^{3}$, comportait une illustration représentant le penseur doté d'une vénérable barbe dans le décor d'une bibliothèque, tenant une tablette votive entre les mains. Diversement réinterprétée, cette image sera popularisée par plusieurs ouvrages au cours du siècle suivant. Elle servit aussi de modèle pour de petits portraits vendus sur des feuilles indépendantes disponibles pour la décoration ou la distraction, et même tissés sur étoffe. Voltaire en aurait placé un dans son oratoire ${ }^{4}$.

La publication du Confucius sinarum philosophus avait donné lieu à d'abondants commentaires. Le Journal des sçavans, qui venait de reparaître après une interruption de dix mois et qui deviendra le périodique de référence des milieux érudits, en avait rendu compte avec éloge le lundi 5 janvier 1688, sous la plume du cartésien Pierre Régis (1632-1707). La lecture de Confucius avait inspiré à Régis la réflexion, jugée provocante par certains, qu'il ne voyait pas que la charité des Chinois fut différente de celle des Chrétiens ${ }^{5}$. Quelques

3. Couplet, 1687. L'ouvrage ne comporte pas d'approbation de la Faculté de théologie. Sur les traducteurs, Philippe Couplet (1622-1693) qui a signé la dédicace à Louis XIV «Ludovico Magno Regi Christianissimo » et la Proëmialis declaratio, Prosper Intorcetta (1626-1696), Christian Herdtricht (1625-1684), François de Rougemont (1624-1676), voir SOMmervogel et De BACKER, 1890-1932 ; Pfister, 1932-1934 ; DEHERGNE, 1973. Avant 1687, des traductions de Confucius avaient déjà été publiées en latin et en français en 1672 et 1673. Elles avaient été contestées par le missionnaire dominicain Domingo Navarrete (1618-1686). Sur le Confucius sinarum philosophus, voir LundBAEK, 1983 et COLLANI, 1990. Pour des traductions modernes des Entretiens de Confucius, voir CHENG, 1981 ; RYCKMANS, 1987 ; LÉVY, 1994.

4. Voltaire, 1883-1885, vol. XVIII, p. 151 ; vol. XL, p. 362.

5. Journal des sçavans, lundi 5 janv. 1688, année 1688, p. 103-105. 
mois plus tard, le même journal avait ouvert ses colonnes au voyageur François Bernier (1625-1688) pour publier une introduction à la lecture de Confucius ${ }^{6}$. Depuis le départ pour la Chine au début de 1685 de six jésuites français, dont quatre avaient été nommés correspondants de l'Académie des sciences, largement rapporté par le Mercure galant, le sujet de la Chine était à la mode ${ }^{7}$. La même année 1688, deux ouvrages avaient diffusé en français des morceaux choisis de la morale de Confucius pour le public peu familier avec le latin ${ }^{8}$.

L'image de Confucius était auréolée de scandale, depuis qu'un héritier spirituel de Michel de Montaigne, François de La Mothe Le Vayer (1588-1672), qui fut précepteur de Louis XIV de 1652 à 1660, avait suggéré dans De la vertu des payens ${ }^{9}$, paru en 1642, qu'en compagnie d'autres philosophes non chrétiens (Socrate, Platon, Aristote, Diogène, Zénon, Pythagore, Épicure, Pyrrhon, Sénèque, Julien l'Apostat), Confucius avait pu être admis au Paradis ${ }^{10}$. Cet ouvrage avait été approuvé par deux censeurs qui ne l'avaient pas trouvé « contraire à la Doctrine de l'Église Catholique Apostolique \& Romaine, ny aux bonnes mœurs ${ }^{11}$ », mais il fut ultérieurement censuré. On raconte que c'est l'auteur lui-même qui alla en personne solliciter l'autorité d'en défendre la lecture. À son libraire qui lui faisait reproche des faibles ventes du livre, il aurait répondu : «Je connais un secret pour en assurer le débit. » Sitôt la censure connue, l'édition aurait été bientôt épuisée ${ }^{12}$ !

Dans La Vertu des payens, on lisait: «Ce n'est pas une petite gloire à Confucius d'avoir mis le Sceptre entre les mains de la Philosophie ; il n'y a que les Philosophes qui gouvernent un si grand empire ${ }^{13}$. »

Comme sources sur la Chine, La Mothe Le Vayer citait Juan Gonzalez de Mendoza (1545-1618) et Nicolas Trigault (1577-1628). C'est dans l'ouvrage du premier que Montaigne avait puisé ses informations sur la Chine. L'ouvrage du second, qui relatait la mission de Matteo Ricci (1552-1610), le fondateur en 1583 de la mission jésuite en Chine, avait connu onze éditions entre 1615 et 1625. Chez Trigault, La Mothe Le Vayer avait pu lire : «La secte de Confucius a pris son origine de la loi de la nature ${ }^{14}$. »

6. «Extrait de diverses pièces envoyées pour étreines à Madame de la Sablière. Introduction à la lecture de Confucius », Journal des sçavans, 7 juin 1688.

7. En 1692, déguisé en docteur chinois, Arlequin fera son apparition sur les tréteaux dans une comédie de Jean-Baptiste Regnard et Charles Dufresny, Les Chinois.

8. Lettre sur la morale de Confucius et La Morale de Confucius philosophe de la Chine.

9. Ouvrage dédicacé «A l'Eminentissime Cardinal de Richelieu ». C'est Richelieu qui avait recommandé La Mothe Le Vayer pour l'éducation du futur Louis XIV, voir MicHAUD, 1843-1858, vol. XXIX, 2, p. 420.

10. LA MOTHE LE VAYER, 1642, deuxième partie.

11. LA Mothe Le VAYER, 1642, approbation du 2 juillet 1641, privilège du 2 août 1641 .

12. Peignot, 1806 , t. I, p. 335.

13. La Mothe Le Vayer, 1642, p. 283.

14. Trigault, 1978, p. 538. 
Les citations de Trigault par La Mothe Le Vayer sur la vie «pleine de sainteté de Confucius » ou sur le pouvoir « absolu » donné aux hommes de lettres en Chine, par opposition au «Japon [qui] se gouverne tout autrement», sont précisément référencées ${ }^{15}$.

Bernier, qui fut l'ami de La Mothe Le Vayer, rapporte qu'il avait surnommé Confucius « le Socrate de la Chine » et qu'il avait de la peine à s'empêcher de dire « Sancte Confuci, ora pro nobis ${ }^{16} »$.

Le célèbre théologien janséniste Antoine Arnauld (1612-1694) composa une réfutation de l'ouvrage de La Mothe Le Vayer ${ }^{17}$ dont le titre du premier chapitre résume très explicitement la problématique qui se noue autour de ces audaces :

«Que les Philosophes et les Payens vertueux n'ont pu être sauvez par la seule connoissance de Dieu \& de sa Providence sans la Foy en Jésus-Christ, \& que de soutenir le contraire, c'est ruiner la nécessité de la Foy en Jésus-Christ établie par les Saintes Ecritures ${ }^{18}$. »

Le 20 mars 1656, les méthodes d'évangélisation de la mission jésuite en Chine sont critiquées dans une brochure anonyme distribuée à la sauvette, adressée «à un provincial» qui ridiculise «leur Keum-Fucum ${ }^{19}$ ». L'identité de l'auteur, protégé par de puissants amis, ne sera percée que trois ans plus tard. Janséniste convaincu, Blaise Pascal avait mis sa plume talentueuse au service d'Arnauld pour accabler de traits mordants les adversaires jésuites de Port-Royal. Neuf Provinciales circuleront jusqu'à ce que la maréchaussée perquisitionne chez l'éditeur qui fut arrêté. Elles furent mises à l'Index, le 6 septembre 1657. Cette date marque le moment où l'opinion publique est prise à témoin d'une controverse, la célèbre Querelle des rites chinois, sur le déclenchement de laquelle les historiens sont divisés ${ }^{20}$, mais qui, jusqu'alors, était restée interne aux ordres religieux. À partir de ce moment, le personnage de Confucius s'identifie à un enjeu d'ordre théologique - la nécessité de la grâce - marquée dans le public par une recherche tâtonnante de l'indépendance de la morale et de la religion. Dans La Morale pratique des Jésuites, Arnauld dénonça « les confucionistes » de la compagnie de Jésus, jugeant « qu'en France comme en Chine, ils sont des docteurs de relâchement ${ }^{21}$ ».

15. La Mothe Le Vayer, 1642, liv. I, chap. v ; Trigault, 1978, p. 94.

16. Journal des sçavans, 7 juin 1688 , p. 26.

17. ARNAULD, 1701. L'ouvrage a été imprimé en France à titre posthume par Louis Ellies Du Pin au moment où la Querelle des rites chinois connaissait une phase aiguë.

18. ARNAULD, 1701, chap. I.

19. Pascal, Cinquième Provinciale. La forme latinisée Confucius ne s'imposera qu'à la suite de l'ouvrage de Philippe Couplet, Confucius sinarum philosophus, paru en 1687.

20. Voir GIRARD, 2000, « Le poids de la Querelle des rites », chap. IV, p. 53 sq.

21. La Morale pratique des Jésuites, 1669-1695, ici 1692, t. VI, préf. 
Le 18 octobre 1700, au travers de la censure de l'ouvrage Nouveaux Mémoires sur l'estat présent de la Chine ${ }^{22}$, du jésuite Louis Le Comte (1655-1728), l'un des six missionnaires partis en 1685 qui était revenu en France en 1693, Confucius est condamné par la Faculté de théologie de l'université de Paris dépendant de la Sorbonne. L'assemblée censura, entre autres, un passage où l'auteur avait écrit que «Confucius fut pleuré de tout l'Empire, qui dès ce temps l'honora comme un Saint ». Le lendemain de cette censure acquise par un vote de 122 voix contre 46, un pamphlet anonyme intitulé L'Enterrement de Confucius réitéré le 19 octobre 1700 circula dans Paris :

«Confucius avoit vécu dans l'erreur, \& étoit mort dans le paganisme ; ses cendres renfermés dans une urne attendoient avec horreur la réunion de son ame, pour estre les tristes compagnes de son malheur éternel ; \& cependant il a trouvé des genies, qui contre leur propre conscience, \& par un entêtement cruel l'avoient ressuscité \& proposé pour modèle aux Chrétiens [...].

«Mais vous êtes avertis, Messieurs, que Confucius est mort en chair et en ame ; que sa sainteté étoit une idolatrie, son humilité un orgüeil, sa modestie une impiété [...].

« Grace à l'illustre Faculté de Théologie de Paris, que l'erreur \& le mensonge ne trompera jamais, nous connoissons presentement la vérité $[\ldots]^{23}$. »

Au tournant du siècle, probablement entretenue par les échos de la querelle, la renommée de Confucius, associée à celle de Socrate, se consolide. C'est à cette époque que Fénelon imagine une rencontre entre les deux philosophes aux Champs-Élysées ${ }^{24}$.

Dans la première moitié du XVIII ${ }^{\mathrm{e}}$ siècle, loin de s'éteindre, la controverse sur les rites chinois couve sous la cendre avec de brusques remontées de flammes. Deux Congregatio particularis de la Sacrée Congrégation de la Propagande de la Foi se réunirent à Rome pour statuer sur la licéité dans le cadre de la foi catholique des cultes rendus à Confucius et aux ancêtres. En traduisant une morale confiante dans la perfectibilité de la nature humaine, présentée comme issue de la loi naturelle, en faisant parvenir à la Cour romaine une attestation de l'empereur confirmant que les rituels traditionnels qui structuraient l'ordre social chinois n'étaient que des « hommages civils », les Jésuites n'introduisaientils pas le ferment qui risquait de nourrir l'athéisme ? Deux légats seront envoyés par la Cour pontificale auprès de l'empereur de Chine pour expliquer la position romaine réprobative. La visite du premier légat, Mr Charles Thomas Maillard de Tournon (1688-1710), reçu par l'empereur Kangxi (règne de 1662 à 1722),

22. Voir Davy, 1950 et Lecomte, 1990, p. 8-16. La censure a également porté sur Le Comte, 1700 et Le Gobien, 1698.

23. Plaquette (STREIT, 1964, $\mathrm{n}^{\circ}$ 2080) conservée à la Bibliothèque nationale de France : O2n.397 ; texte complet transcrit in LANDRY-DERON, 2002, p. 101-102.

24. FÉNELON, 1970, p. 296-306. 
deuxième empereur mandchou de la dynastie Qing qui avait conquis la Chine en 1644 , tourna au désastre ${ }^{25}$. L'empereur exigea un certificat d'accréditation des missionnaires délivré après la signature d'un formulaire d'approbation des cultes traditionnels. Le fils et successeur de Kangxi, l'empereur Yongzheng (règne de 1723 à 1735) proscrira la prédication du christianisme en 1724, expulsant les missionnaires vers Canton puis Macao, ne gardant à la Cour que les jésuites dont les compétences scientifiques et techniques lui étaient utiles.

Ces affaires chinoises entretinrent un émoi considérable en Europe ${ }^{26}$. En 1742, les rites chinois (et malabares) furent condamnés par la bulle Ex quo singulari du pape Benoît XIV. La question des rites ne sera reconsidérée par Rome que sous les pontificats de Pie XI et Pie XII (1922-1939) ${ }^{27}$.

Lorsque Lavicomterie prend la plume en 1788, dans l'imaginaire populaire marqué depuis 1750 par la montée de l'esprit philosophique des Lumières, Confucius, rejeté par l'orthodoxie romaine, incarne une figure charismatique antonyme du modèle chrétien. Sa renommée, acquise au prix de perceptions brouillées, s'est établie comme symbole d'une résistance à l'intolérance du pouvoir établi. Voltaire orchestra cette ambiguïté en consacrant à Confucius le quatrain suivant :

« De la seule raison salutaire interprète

Sans éblouir le monde, éclairant les esprits

Il ne parla qu'en Sage et jamais en Prophète

Cependant on le crut et même en son pays ${ }^{28}$. »

\section{LE TRADUCTEUR PRÉSUMÉ}

Le père Dominique Parrenin (1665-1741) fut l'un des membres de la mission jésuite française en Chine où il arriva fin 1698 sur le premier bateau français, L'Amphitrite, qui effectua une traversée sans escale entre un port français (La Rochelle) et Canton. Parrenin avait été recruté avec une douzaine d'autres missionnaires par le père Joachim Bouvet (1656-1730), l'un des pionniers de la mission française. Ces pionniers étaient partis en 1685 et Bouvet était revenu en France en 1697 (quatre ans après le retour du père Le Comte) recruter des renforts pour étoffer les rangs d'une mission qui cherchait à acquérir son

25. ÉTIEMBLE, 1966, p. $111 s q$.

26. Voir Voltaire, « Disputes sur les cérémonies chinoises. Comment ces disputes contribuèrent à faire proscrire le christianisme à la Chine», chapitre final du Siècle de Louis XIV, in VolTAIRE, 1883-1885, vol. XV, p. 76-84.

27. MinAmiki, 1985, p. $183 \mathrm{sq}$.

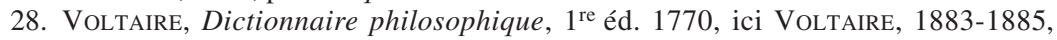
vol. XVIII, p. 151. 
autonomie par rapport à la mission jésuite portugaise. Ce statut autonome fut octroyé en 1700. L'Amphitrite emportait également un architecte, le frère Charles de Belleville (1656-1730) qui fit bâtir entre 1699 et 1703 l'église du SaintSauveur à Pékin sur un terrain offert aux jésuites français par l'empereur Kangxi. Un peintre italien, Gio. Gherardini, faisait aussi partie du voyage sur lequel il a laissé un récit ${ }^{29}$. Gherardini avait décoré la maison professe des jésuites du faubourg Saint-Antoine à Paris. Sa fresque sur l'apothéose de saint Louis au-dessus du grand escalier faisait «un coup d'œil admirable ${ }^{30}$ ». L'église du Saint-Sauveur a été endommagée par un incendie au XIX ${ }^{\mathrm{e}}$ siècle.

Auprès du public européen, le nom de Parrenin a été rendu familier par les recueils des Lettres édifiantes et curieuses, véritable vitrine des missions jésuites dans le monde, qui parurent selon une périodicité variable, annuelle ou tous les deux ou trois ans, entre 1702 et 1776. De 1709 à sa mort, la parution des Lettres édifiantes et curieuses fut supervisée par le père Jean-Baptiste Du Halde (16741743) qui eut également la haute main sur la vaste compilation Description de l'empire de la Chine et de la Tartarie chinoise parue en 1735 qui restera pendant près d'un siècle l'ouvrage de référence sur la Chine auprès des érudits de l'Europe entière $^{31}$. Dix lettres de Parrenin ont été publiées dans les Lettres édifiantes et curieuses $^{32}$ et il fit partie des vingt-sept missionnaires qui contribuèrent à la Description de Du Halde.

Parrenin s'était illustré comme l'un des plus talentueux missionnaires de Pékin. Kangxi l'avait chargé de traduire en mandchou un traité d'anatomie rédigé par un académicien français, Pierre Dionis (1643-1718) ${ }^{33}$. L'empereur Yongzheng avait gardé Parrenin à la Cour au moment de l'interdiction de prédication du christianisme, en qualité d'interprète. Il officia à ce titre pour les ambassades du Portugal et de Russie reçues à Pékin en 1726 et 1727. C'est la correspondance que Parrenin entretint avec l'Académie des sciences, spécialement avec son directeur, Jean-Jacques Dortous de Mairan (1678-1771) ${ }^{34}$, à laquelle Du Halde fait écho ${ }^{35}$, qui le plaça dans une position particulièrement en vue. La liaison entre Parrenin et l'Académie des sciences débuta en 1724,

29. GHERARDini, 1700 .

30. Piganiol de La ForCE, 1765, vol. V, p. 23.

31. Duhalde (sic) est inclus dans le Catalogue de la plupart des écrivains français qui ont parû dans le Siècle de Louis XIV pour servir à l'histoire littéraire de ce temps, Voltaire, 1883-1885, vol. XIV, p. 68. Sur la longévité de l'impact de la Description, voir LANDRY-DERON, 2002, p. 37-38.

32. L.E.C., 1713, rec. X, p. 405-412; 1720, rec. XIV, p. 431-448; 1726, rec. XVII, p. 1-62 et 344-346; 1728, rec. XVIII, p. 1-205 et 248-311; 1729, rec. XIX, p. 1-205 et 206-264; 1731, rec. XX, p. 1-45; 1734, rec. XXI, p. 76-183.

33. L'Anatomie de l'homme suivant la circulation du sang et les dernières découvertes, Paris, 1690. Copie de cet ouvrage, Bibliothèque nationale de France, fonds mandchou 289.

34. Gillipsie, 1981, vol. IX, p. 33-34.

35. Du Halde, 1735, préf., p. IV et 1736, préf., p. XII. 
du temps de Fontenelle (1657-1757), auquel Parrenin adressa des travaux scientifiques qui furent publiés dans les Lettres édifiantes et curieuses et par Réaumur (1683-1757) dans les recueils de l'Académie des sciences ${ }^{36}$. En 1728, Dortous de Mairan, prit l'initiative d'écrire à Parrenin pour lui réclamer des éclaircissements sur des «doutes » savants qu'il se posait sur la Chine. Trois lettres furent échangées de part et d'autre. Du Halde fit paraître les réponses de Parrenin dans les Lettres édifiantes et curieuses ${ }^{37}$ en résumant les questions posées par Mairan. Après la mort de Du Halde, jugeant que le texte de ses questions avait été tronqué par ce dernier, Mairan prit l'initiative de le faire publier en $1759^{38}$. Cette publication reçut une attention toute spéciale du fait de la résonance que lui donna Voltaire dans le Siècle de Louis XIV :

« Il [l'empereur de Chine Kangxi] garda [quelques missionnaires jésuites] auprès de lui, entre autres le jésuite nommé Parennin [sic], dont j'ai déjà fait l'éloge, homme célèbre par ses connaissances et par la sagesse de son caractère, qui parlait très bien le chinois et le tartare. Il était nécessaire, non seulement comme interprète, mais comme bon mathématicien. C'est lui qui est principalement connu parmi nous par les réponses sages et instructives sur les sciences de la Chine aux difficultés savantes d'un de nos meilleurs philosophes. Ce religieux avait eu la faveur de l'empereur Kang-hi [Kangxi] et conservait celle d'Young-tching [Yongzheng]. Si quelqu'un avait pu sauver la religion Chrétienne, c'était lui ${ }^{39}$.»

36. L.E.C., 1726, rec. XVII, p. 344-446; Histoires et Mémoires de l'Académie des sciences, 1726 : Histoire, p. 17-20 ; Mémoires, p. 302-305 et 377-402. L'original autographe de deux lettres de Parrenin adressées à Fontenelle - Pékin, ${ }^{\text {er }}$ mai 1723 et 20 août 1724 - est conservé à l'Institut de France : Ms 2698 fº 16-26, voir Grover, 1980. L'Académie s'est semble-t-il offusquée que Du Halde n'ait pas donné la primauté du travail de Parrenin à l'Académie en le publiant d'abord dans les Lettres édifiantes et curieuses, voir HsiA, 1999, p. 325 ; LANDRY-DERON, 2002, p. 148.

37. $1^{\text {re }}$ lettre de Mairan, 14 oct. 1728 - réponse de Parrenin, 10 oct. 1731, in L.E.C., 1734, rec. XXI, p. 76-183. La reprise de la correspondance entre l'Académie des sciences et Parrenin est mentionnée par l'Académie, année 1732, Histoire, p. 21-25. $2^{\mathrm{e}}$ lettre de Mairan, 29 sept. 1732 - réponse de Parrenin, 28 sept. 1735, in L.E.C., 1739, rec. XXIV, p. 9-31. $3^{\text {e }}$ lettre de Mairan, 22 oct. 1736 - réponse de Parrenin, 20 sept. 1740, in L.E.C., 1743 , rec. XXVI, p. 1-85.

38. MAIRAN, 1759. De son vivant, en 1770, une version augmentée parut à l'imprimerie royale. Je n'ai pas vu cette édition qui figure dans le Catalogue des livres de feu M. de Mairan, $\mathrm{n}^{\circ}$ 3033. C'est cette édition que cite Cornelius DE PAUw, 1773, vol. I, p. 58. L'ouvrage que Nyon l'aîné fit paraître en 1782 sous un titre fallacieux est semblable à l'édition de 1759 (comparaison établie sur les exemplaires Bibliothèque nationale de France Rés.O2n.56 et Rés.O2n.50).

39. Voltaire, 1883-1885, vol. XV, p. 82-83. 
D'après Louis Moland, cet alinéa date de $1768^{40}$. L'allusion aux « difficultés savantes de l'un de nos meilleurs philosophes » fait référence aux questions de Dortous de Mairan, dont Voltaire, qui en faisait grand cas, a écrit qu'il ne connaissait personne «qui approfondisse plus et expose mieux ${ }^{41}$ ». Mairan avait travaillé à introduire les théories de Newton en France.

À la mort de Parrenin en 1743, Mairan lui avait rendu hommage dans une séance publique de l'Académie des sciences :

« Nous ne saurions ici nommer le P. Gaubil [autre membre de la mission jésuite française à Pékin (1689-1759)] avec qui nous sommes depuis plusieurs années en correspondance, sans nous rappeler le souvenir de celui qui nous a procuré cet avantage, le P. Parennin [sic], cet homme rare qui joignit aux vertus héroïques du Missionnaire les qualités \& les connoissances les plus estimables du Savant. Il mourut à Pékin, à l'âge de soixante-seize ans accomplis, regretté du Chef et des Membres de ce vaste Empire à la conversion duquel il avoit consacré ses jours, pleuré par le peuple, par les Infidèles même qu'il n'avoit pu convertir ${ }^{42}$. »

La liaison entre la mission jésuite française de Pékin et l'Académie des sciences, voulue par l'autorité royale qui versait des « pensions » pour l'entretien des missionnaires, était considérée de la plus haute importance par les supérieurs de Pékin. Dans une lettre de 1727, on trouve la réflexion suivante :

« Je sais encore qu'un mot de louange de leur [les Académiciens] part fait plus d'honneur à la Compagnie de Jésus que tous les éloges que les jésuites pourraient faire de leurs confrères; et que si jamais ils nous attaquaient en quelque matière que ce fut de leur ressort, tout le public serait pour eux ${ }^{43}$. »

Une dizaine de mentions de Parrenin, uniment flatteuses, émaillent les Euvres complètes de Voltaire ${ }^{44}$, où il fait peu de doutes que Lavicomterie puisa sa familiarité avec l'activité de Parrenin et la vraisemblance de l'image qu'il utilisera du connaisseur autorisé de la Chine. Ce qui frappe est la constance avec laquelle Voltaire a évoqué Parrenin, utilisant toujours les mêmes adjectifs pour le qualifier. Dès l'Essai sur les mours (dans les années quarante du XVIII ${ }^{\mathrm{e}}$ siècle),

40. Voltaire, 1883-1885, vol. XV, p. 82-83, n. 1. Cet ajout de Voltaire motiva sans doute la réédition des Lettres de Mairan au R. P. Parrenin de 1770 et l'entreprise de Nyon de 1782.

41. Cité par Roche, 1969 , p. 58, n. 5.

42. Histoire de l'Académie des sciences, année 1743, p. 151.

43. Lettre du P. Jean-Baptiste Jacques (1688-1728) au P. Étienne Souciet (1671-1744), procureur des missions d'Orient, $1^{\mathrm{er}}$ nov. 1727, Revue de l'Extrême-Orient, t. III, 1887, p. 222. La remarque intervient dans le contexte évoqué supra, n. 36 et sonne probablement comme une critique de Du Halde.

44. Voltaire, 1883-1885, vol. X, p. 414 ; vol. XI, p. 56 ; vol. XVIII, p. 153 ; vol. XXIX, p. 125 ; vol. XLIX, p. 454, 475 et 499. 
il en avait parlé comme « l'un des plus savants et des plus sages missionnaires ${ }^{45}$ ». Il reprit l'expression dans les dernières années de sa vie, à propos de l'opinion soutenue par Joseph de Guignes père (1721-1800) sur une origine commune des Égyptiens et des Chinois, qu'il fondait sur la proximité qu'il avait cru percevoir entre les hiéroglyphes (que personne encore n'avait déchiffrés) et les caractères chinois :

«La manie des chimères a été poussée jusqu'à faire semblant de croire que les Chinois sont une colonie d'Égyptiens, quoiqu'en effet il n'y ait pas plus de rapport entre ces deux peuples qu'entre les Hottentots et les Lapons, entre les Allemands et les Hurons. Cette prétention ridicule a été entièrement confondue par le P. Parennin, l'homme le plus savant et le plus sage que la folie envoya à la Chine, et qui, ayant demeuré trente ans à Pékin, était plus en état que personne de réfuter les nouvelles fables de notre Europe. Cette puérile idée que les Égyptiens allèrent enseigner aux Chinois à lire et à écrire vient de se renouveler encore $[\ldots]^{46}$. »

Il est intéressant de noter que le dernier passage a été rédigé au moment de la suppression de la compagnie de Jésus par le bref Dominus ac redemptor du 23 juillet 1773 du pape Clément XIV (pontificat 1769-1775), dix ans après la proscription de 1762 de la Compagnie en France, et la mesure similaire prise au Portugal et en Espagne respectivement en 1759 et 1767.

Si on essaye donc de reconstituer ce qu'évoquait le nom de Parrenin en 1788 lorsque Lavicomterie usurpa son identité, on constate que malgré la disparition de la vie nationale en tant qu'institut religieux de la compagnie de Jésus, la célébrité de certains de ses membres ne s'était pas éteinte. Paradoxalement, elle était entretenue chez les voltairiens.

La condamnation par l'autorité romaine de l'interprétation des Jésuites des rites chinois fournit un combustible inattendu à l'agrégation de l'image de Confucius dans le corps des réflexions sur la loi naturelle. Le rejet de Confucius hors du champ de l'orthodoxie ouvrit la voie à une laïcisation de la société ${ }^{47}$. La séduction exercée par une morale ignorant un péché originel, perçu comme une malédiction oblitérant l'avenir de l'homme, rencontrait la vision optimiste des Lumières et sa foi dans le progrès.

En 1788, la mission jésuite française subsistait toujours à Pékin, financée par la cassette royale. Par décision exceptionnelle, Louis XV avait décidé de pourvoir jusqu'à leur mort à l'entretien des missionnaires déjà sur place au moment de la proscription. Après la confirmation de la proscription de novembre 1764,

45. Voltaire, Essai sur les mours et l'esprit des nations, $1^{\text {re } e ́ d . ~ 1740, ~ i c i ~ V o l t a i r e, ~}$ 1883-1885, vol. XI, p. 173.

46. Voltaire, Fragments historiques sur l'Inde et sur le général Lally, (1773-1774), art. 6, in Voltaire, 1883-1885, vol. XXIX, p. 107. Allusion à DE Guignes, 1759.

47. HAZARD, 1994, p. 30-32. 
deux jeunes convertis chinois, Ko (Gao Leisi) et Yang (Yang Dewang), qui étaient venus faire des études en France en 1754 dans les collèges jésuites, repartirent en Chine en janvier $1765^{48}$. On sait que c'est à l'occasion de leur départ que Turgot rédigea ses Questions sur la Chine et ses Réflexions sur la formation et la distribution des richesses ${ }^{49}$. Sous la protection de ministres, les derniers survivants de la mission continuaient à envoyer du matériau d'information en France. L'activité des pères Jean Joseph Marie Amiot et Pierre-Martial Cibot dans les deux décennies qui précédèrent la Révolution sera évoquée plus loin.

L'idée de Lavicomterie d'un pastiche de Confucius et de Parrenin reflète sans doute fidèlement l'ambivalence de l'époque au sujet de la proscription de la compagnie de Jésus. Révérence pour les connaissances des plus érudits, regret souvent formulé pour la baisse de la formation des jeunes consécutive à la fermeture des collèges jésuites, mais aussi reconnaissance, fût-ce comme ici par la dérision, de son rôle de vecteur d'ouverture sur le monde.

\section{L'ÉDITEUR}

C'est dans ce rôle que se campe Lavicomterie. Il pousse le soin, à la fin de l'Avertissement, jusqu'à rendre compte des motifs du retard de la publication !

«Il paraît par plusieurs passages, surtout du commentaire, que cet Ouvrage était fait pour paraître il y a quelques années ; mais apparemment quelques circonstances empêchèrent le père Parennin de le publier ${ }^{50}$. »

Lavicomterie suggère même qu'il aurait trouvé ce post-scriptum à la fin du commentaire qu'il attribue au missionnaire :

« Je déclare formellement n'avoir eu en vue, dans ma traduction du Poëme de Confucius, dans mon Commentaire \& les Dialogues qui sont à la fin de chaque partie, que les hommes qui ont déshonoré le Sacerdoce, la Magistrature ; les uns souvent par un fanatisme atroce $\&$ sanguinaire, \& toujours par un zèle qui n'étoit pas selon la Science ${ }^{51}$; les autres, par une Barbarie que les Loix même \& les vrais Magistrats désapprouvent. Comme cet Ouvrage ne doit paraître qu'après ma mort, je le mets d'avance sous leur protection sacrée. J'ai cru servir le Gouvernement \& l'humanité. Si j'arrête seulement une fois la main, prête à signer une oppression, une iniquité cruelle, je serai payé de mon travail : \& malheur à qui pourroit s'en offenser !

48. Pfister, 1932-1934, ici 1934, notices 427-428 ; Dehergne, 1965.

49. TuRGOT, 1966 , t. I, p. 7-67 et 310-321.

50. [LAVICOMTERIE], 1788, p. VII-VIII.

51. Souligné dans le texte. 
«L'Editeur respecte, ainsi qu'il le doit, la Religion \& ses Ministres [...]. Il espère que les gens de bien lui sauront gré d'avoir mis au jour cet Opuscule d'un homme que l'humanité doit regretter ${ }^{52}$. »

Louis-Thomas Hébert, qui signait La Vicomterie de Saint-Samson avant 1789 et préféra raccourcir son nom par la suite, serait né, d'après la notice sur sa vie rédigée par Nicaise Goujon ${ }^{53}$, vers 1732, probablement en Normandie. Il fit des études de droit. En 1779, il concourut pour un Éloge de Voltaire proposé par l'Académie qui ne fut pas couronné mais qu'il fit imprimer en 1782, en le faisant suivre de la lettre que Frédéric II de Prusse lui avait envoyée pour le remercier de lui avoir fait parvenir son texte ${ }^{54}$. En 1789, il écrit une ode à la liberté et s'adonne à l'écriture pendant toute la période révolutionnaire, publiant coup sur coup Du peuple et des rois (1790), ouvrage qui sera régulièrement réédité dans les périodes insurrectionnelles du XIX ${ }^{\mathrm{e}}$ siècle, Les Droits du peuple sur l'Assemblée nationale (1791), puis une série de volumes d'ambition historique, Les Crimes des rois de France depuis Clovis jusqu'à Louis XVI (1791) qui sera traduit en anglais et en allemand et suivi en 1792 d'une édition augmentée des « derniers crimes de Louis XVI », puis Les Crimes des papes depuis saint Pierre jusqu'à Pie VI (1792), Les Crimes des empereurs d'Allemagne depuis Lothaire I ${ }^{e r}$ jusqu'à Léopold II (1793), Les Crimes des empereurs Turcs depuis Osman I ${ }^{e r}$ jusqu'à Sélim IV (1794).

À partir du 21 septembre 1792, il représenta le département de Paris à la Convention nationale où il siégea à la Montagne. Le 21 août 1793, il fut nommé au Comité de sûreté générale avec Robespierre et Saint-Just. La Convention fit imprimer un discours qu'il prononça le 17 vendémiaire an III (septembre 1794) intitulé Essai de morale calculée où il proposait la rédaction d'un code de lois appuyées sur la morale et la vertu et la création de « chaires de morale calculée, à la place de ces tréteaux de théologie qui ont si-longtemps désolé la terre ${ }^{55}$ ». On notera qu'en habitué des emprunts parodiques qui suivent au plus près les succès d'autrui, Lavicomterie reprit le titre de l'Essai de politique et de morale calculée de Pierre François Hugues d'Hancarville, publié en 1759.

Après l'arrestation de Louis XVI, Lavicomterie prit position avec ardeur en faveur de sa mise en accusation. La Convention fit imprimer le discours qu'il prononça le 3 décembre 1792 : «Peut-on demander aujourd'hui : le ci-devant roi peut-il être jugé, cette seule question est un outrage à la raison. »

52. [LAVICOMTERIE], 1788, p. 126-127.

53. Notice sur Lavicomterie et ses ouvrages, placée en tête des éditions de 1834 des Crimes des rois de France, p. VIII et Du peuple et des rois, p. II. Voir également Michaud, 1843-1858, vol. XLIII, p. 301-302 et GIBOURY, 1989, p. 237-238.

54. LAVICOMTERIE, 1782.

55. LAVICOMTERIE, 1794. Bibliothèque nationale de France : L38e pièce 985. 
Lavicomterie justifie sa position en invoquant la lâcheté et la conspiration dont à ses yeux Louis XVI s'était rendu coupable :

« Il est démontré que de l'antre des Tuileries se conduisoient toutes les trames qui ont mis la République au bord du précipice. Si les subalternes ont péri, frappons le chef des conspirateurs \& que la loi, désormais inexorable, fasse tomber sa tête.

« Devant ses collègues, il expliqua l'apparente contradiction de son attitude :

— Je déteste, j'ai combattu les barbaries judiciaires ; mais quand le salut public est compromis, l'indulgence est un crime. »

Sa détermination fut sans faille : « Je poursuivrai ce lâche assassin, ce parricide national, jusqu'au moment où, sous la hache de la loi, j'aurai vu rouler sa tête au Carrousel ${ }^{56}$. »

La veille du vote sur la mort, le 15 janvier 1793, jugeant sans objet la demande de ratification de la sentence par les assemblées populaires, il réclama la question préalable à l'appel au peuple :

«Que le président dise Louis est convaincu de n'avoir cessé depuis quatre ans de conspirer contre la République. La loi punit de mort les conspirateurs : Louis doit-il la subir ? Que chacun monte à la tribune et prononce oui ou non, sans commentaire ${ }^{57}$.»

À la chute de Robespierre, il déserta la Convention. Le 9 prairial an III (28 mai 1795), il fut décrété d'arrestation mais réussit à se cacher, avant de se déclarer aux autorités qui l'assignèrent à résidence. Il bénéficia de la loi d'amnistie du 4 brumaire an IV. Sans aucun revenu, il sombra dans la misère, avant d'obtenir vers la fin du Directoire et jusqu'à sa mort le 25 janvier 1809 un petit emploi de 1000 à 1200 francs, nous dit-on, à la Régie du timbre.

Dans Des droits du peuple sur l'Assemblée nationale, Lavicomterie se prévalut de son Code de la nature pour remarquer qu'il n'avait pas attendu la Révolution pour «détester les tyrans politiques et religieux ${ }^{58}$ ». Dans La République sans impôt, paru en 1792, il se prononça contre l'esclavage des Noirs. À cette date, il renouvelait son opposition à la peine de mort ${ }^{59}$.

Si le texte de Lavicomterie a parfois été attribué de manière erronée à CharlesGeorges Coqueley de Chaussepierre ${ }^{60}$, la confusion provient sans doute du fait que c'est ce juriste qui en fit le compte rendu dans le Journal des sçavans ${ }^{61}$.

56. Réflexions du citoyen Lavicomterie sur le procès criminel du ci-devant roi [3 déc. 1792].

57. LAVICOMTERIE, L'Appel au peuple est un paradoxe [15 janv. 1793].

58. LAVICOMTERIE, 1791a, p. 101, n. 1.

59. LAVICOMTERIE, $1792 \mathrm{~b}$.

60. Voir supra n. 2.

61. Journal des sçavans, oct. 1788, p. 671-673. 
Coqueley de Chaussepierre ne fut nullement dupe du plagiat qu'il ne laissa pas ignorer :

« Il nous serait difficile de croire, \& par conséquent d'assurer à nos lecteurs que l'ouvrage dont on vient de lire le titre fut celui de Confucius, \& qu'il ait été réellement traduit et commenté par le Père Parennin; l'Auteur qui ne se nomme pas, ne donne aucun renseignement sur cela, parce que sans doute il lui a paru difficile de faire connoître à ses lecteurs les moyens par lesquels il avoit pu se procurer les manuscrits de Confucius, et la traduction et les commentaires de Parennin; quoiqu'il en soit, on ne peut disconvenir qu'il n'ait choisi \& emprunté deux noms bien célèbres, \& nous croyons pouvoir assurer qu'en lisant son ouvrage on le trouvera fort analogue à l'esprit \& aux opinions de ses modeles ${ }^{62}$. »

Coqueley de Chaussepierre était avocat au parlement de Paris et censeur royal pour la jurisprudence ${ }^{63}$. Le deuxième chant du poème de Lavicomterie qui condamne la peine de mort l'a particulièrement séduit. En rappelant que plusieurs savants et jurisconsultes ont souhaité l'abolition de la peine de mort, Coqueley de Chaussepierre fait probablement voix à son opinion personnelle et à la vigueur du courant d'opinion qui se manifeste en cette dernière année du règne de Louis XVI. La critique se conclut par un éloge des « motifs très louables » de l'auteur du texte ${ }^{64}$.

\section{LE TITRE EMPRUNTÉ}

À l'article près, le titre du poème Le Code de la nature avait déjà été utilisé avant Lavicomterie par un auteur dont l'anonymat n'avait pas été clairement percé. Ce petit in-12 était paru à Amsterdam en 1755, avec, en guise d'adresse, la mention «Partout, chez le vrai Sage». Son titre complet est Code de la nature, ou le véritable esprit de ses lois, de tout temps négligé et méconnu. Le répertoire alphabétique d'auteurs La France littéraire paru en 1769 1'avait attribué à Diderot ${ }^{65}$ (1713-1784) et l'édition d'Amsterdam des Euvres complètes de Diderot publiées en cinq tomes en 1773 l'avait même inclus dans le tome II. On sait aujourd'hui que le véritable auteur en est Morelly ${ }^{66}$. Joseph-Marie Quérard suggère que l'attribution à Diderot, courante à l'époque, viendrait d'une confusion avec les Pensées sur l'interprétation de la nature publiées

62. Journal des sçavans, oct. 1788, p. 671.

63. Michaud, 1843-1858, vol. IX, p. 165-166.

64. Journal des sçavans, oct. 1788, p. 673.

65. La France littéraire ou almanach des beaux-arts, 2 vol.

66. Lichtenberger, 1895, p. 104 ; DocKes, 1985, p. 63-65 ; Grente, 1996, p. 945. 
en $1754^{67}$. Au cours de son procès, en 1797, Gracchus Babeuf justifiera la Conjuration des Égaux en ce réclamant du Code de la nature qu'il attribuait à Diderot.

L'inspiration de Lavicomterie est clairement puisée dans le Code de la nature de Morelly. L'idée d'un faux poème de Confucius se calque sur la démarche de Morelly qui avait rédigé en 1753 une utopie donnée comme une traduction de l'indien, La Basiliade, ou naufrage des îles flottantes. L'emprunt du titre est un clin d'œil ou un hommage à celui de Morelly dont la force dut frapper Lavicomterie, comme elle avait impressionné Friedrich-Melchior Grimm qui l'avait noté dans sa Correspondance : «Quel titre ! et combien il faut de méditation, de recueillement, de vertu d'âme, combien de profondeur dans l'esprit, d'élévation et de simplicité dans le cœur pour être l'interprète du Code de la nature ${ }^{68}$. »

Dans le premier ouvrage de Morelly, les « îles flottantes » représentaient les préjugés. Le Code de la nature de Morelly, antérieur de quelques mois au Discours des fondements de l'inégalité parmi les hommes de Jean-Jacques Rousseau, replace la société sous l'empire de la nature. C'est l'oubli de la loi naturelle qui est à la source du malheur de l'homme. Dans l'état de nature, l'idée de la bienveillance, active ou passive, précède tout autre idée, y compris celle de la divinité. Par souci de sa conservation, l'homme est contraint à la bienveillance. Les lois, qui entérinent la propriété privée, pervertissent l'homme. La conquête du bonheur humain dans la liberté éclaire le conflit entre la raison et les passions. Morelly énonce les idées ultérieurement revendiquées par les fouriéristes qui élaborent sur l'état de nature une philosophie sociale radicale fondée sur l'égalité et l'abolition de la propriété. En 1845, Friedrich Engels aurait envisagé de faire figurer le Code de la nature de Morelly dans un projet de bibliothèque socialiste ${ }^{69}$.

Chez Morelly et Lavicomterie, interprètes de la nature, les leçons de cette égérie sont contredites et flétries par la morale et les institutions sociales et religieuses. On entrera plus loin dans le détail de l'élaboration des idées de Morelly dans le pastiche de Lavicomterie. Il suffit ici de remarquer que sur l'idée de la bonté naturelle de l'homme transmutée sur le « sens de l'humain » confucéen, le ren - qui ne remet pas en cause les hiérarchies sociales - l'image de Confucius peut s'agréger au ferment des idées hardies développées dans une littérature réfugiée par nécessité dans tout anonymat susceptible de compliquer la tâche des censeurs.

67. QUÉRARD, 1964, vol. I, p. 938.

68. GRIMM, 1877-1882, vol. II, p. 489. Le passage date de février 1755.

69. Notation de V. P. Volguine dans sa préface à l'édition de 1953 du Code de la nature de Morelly, voir MoRelly, 1755. 
Sur un siècle, entre 1688 et 1791, le sujet de la Chine a fait en France l'objet de trois vagues de publications, comptabilisées à partir des comptes rendus parus dans le Journal des sçavans. La première se situe entre 1685 et 1710. Elle comprend douze comptes rendus. Elle inclut le Confucius sinarum philosophus et ses succédanés en français et les publications des jésuites envoyés par Louis XIV en Chine. La seconde se situe entre 1730 et 1745 . Elle est contemporaine de la condamnation des rites chinois. Elle comprend quinze comptes rendus dont ceux qui concernent la Description de la Chine de Du Halde. La troisième vague se situe dans les deux décennies qui précèdent la Révolution française. Le pamphlet de Lavicomterie qui sort des presses en 1788 s'inscrit dans cette troisième vague, qui ressemble à une déferlante, tant les événements éditoriaux se succèdent. Le Journal des sçavans comprend cinquante et un comptes rendus d'ouvrages sur la Chine dans ces vingt années ${ }^{70}$.

Le phénomène est relancé en 1770 par deux traductions des membres de la mission jésuite française à Pékin dont la publication a été assurée par De Guignes. La première est une traduction posthume du père Antoine Gaubil de l'un des classiques chinois, le Chou-King (Shujing). La seconde est une traduction d'un poème en mandchou de l'empereur Qianlong (règne de 1736 à 1796), fils et successeur de Yongzheng, Éloge de la ville de Moukden. Moukden (ancien nom de la ville de Shenyang dans la province du Liaoning) est le berceau des Mandchous de la dynastie Qing qui régnaient sur la Chine depuis 1644. Elle abrite le tombeau du fondateur de la dynastie, Taizong, mort en 1643 juste avant la conquête de Pékin. Qianlong rédigea cette pièce en 1748 pour rappeler ses racines à l'aristocratie mandchoue ${ }^{71}$.

En montrant la révérence de l'empereur pour ses ancêtres, la traduction, due au père Amiot arrivé en Chine en 1740, qui avait été autorisé à rester à Pékin après la proscription de la compagnie de Jésus ${ }^{72}$, parut à certains comme une tentative de réhabilitation des interprétations jésuites des cultes chinois. Elle relança le débat sur l'athéisme des Chinois. Cornelius de Pauw (1739-1799) sortit en 1772 ses Recherches philosophiques sur les Égyptiens et les Chinois dont la quatrième partie reprend la question en se montrant très critique vis-àvis des travaux des Jésuites en général et des Chinois en particulier. Voltaire

70. Milsky, 1977, vol. I, p. 375 et graphique, vol. II, p. 786 ; Touboul-Bouyeure, 1993. Cette comptabilité basée sur une publication officielle exclut les pamphlets rédigés par partisans et adversaires des rites. En créant le scandale, ces pamphlets focalisèrent néanmoins l'intérêt sur la Chine. On en trouvera une bibliographie dans SOMMERvOGEL et DE BACKER, 1890-1932, vol. X, col. 1539-1544.

71. Un exemplaire de l'original a été envoyé à Paris, Bibliothèque nationale de France : fonds mandchou 110.

72. PfISTER, 1932-1934, ici 1934, notice 392 ; RochemonteIX, 1915. 
suivait depuis trop longtemps les débats sur la Chine pour laisser sa plume silencieuse sur le sujet. Il répondit à Pauw en 1776 sous le couvert d'un anonymat bénédictin ${ }^{73}$. Trois de ces lettres, ultérieurement rassemblées sous le titre Lettres chinoises, évoquent le poème de Qianlong ${ }^{74}$.

En 1776, fut lancée la collection Mémoires concernant les Chinois patronnée par le ministre Henri Bertin (1719-1792). L'édition rassemble des documents rédigés principalement par les derniers survivants de la mission, les pères Jean Joseph Marie Amiot (1718-1793), Pierre-Martial Cibot (1727-1780) et Louis Bourgeois (1723-1792) ${ }^{75}$. La parution se poursuivit au rythme d'un volume par an. En 1788, on en était au treizième volume. Il sortit quinze volumes jusqu'en 1791. La Révolution et la mort des rédacteurs interrompirent la publication. Mais en 1814, l'orientaliste Silvestre de Sacy (1758-1838) reprit ce titre qui avait acquis du prestige pour faire paraître deux inédits de Gaubil.

Une année après la parution du premier volume des Mémoires concernant les Chinois, en 1777, est lancée par souscription la traduction de l'ouvrage d'un autre missionnaire de Pékin, le père de Mailla (1669-1748) ${ }^{76}$ : l' Histoire générale de la Chine, qui comprend treize volumes et dont la parution s'étala jusqu'en 1785. Le manuscrit de ce travail avait été envoyé en France en 1737 au secrétaire de l'Académie des inscriptions, Nicolas Fréret (1689-1743) qui en avait envisagé la publication. La mort de Fréret avait interrompu le projet dont la réalisation était très attendue par le milieu savant. Le flambeau fut repris par un ancien jésuite, l'abbé Jean-Baptiste Grosier (1743-1823), assisté par Michel-Ange-André Leroux Deshauterayes (1724-1795), qui avait été, avec Joseph De Guignes, l'élève d'Étienne Fourmont (1683-1745). Fourmont avait fait graver à l'imprimerie royale des caractères chinois dont il s'était servi pour imprimer une grammaire et le catalogue des livres chinois de la Bibliothèque royale ${ }^{77}$. La liste des souscripteurs de la traduction du père de Mailla a été publiée en tête du premier volume. Ce document aide à dessiner le profil sociologique du milieu intéressé par la Chine après la proscription de la compagnie de Jésus.

73. [Voltaire], Lettres à M. Pauw par un bénédictin, voir Voltaire, 1883-1885, vol. XXIX, p. 451-479.

74. VoltaIRE, Lettre I : « Sur le poëme de l'Empereur Kien-long »; Lettre II : « Réflexions de Dom Ruinard sur la Vierge dont l'Empereur Kien-long descend»; Lettre III : « Sur l'athéisme de la Chine », voir Voltaire, 1883-1885, vol. XXIX, p. 451-463.

75. Pfister, 1934, notices 419 et 430.

76. PFISTER, 1934, notice 269.

77. Les caractères chinois gravés par Fourmont sur ordre du régent sont conservés à l'imprimerie nationale. Ils servirent en 1813 à De Guignes pour imprimer, sur ordre de Napoléon, le premier dictionnaire chinois-latin-français. 
L'Histoire générale de la Chine touche un milieu étroit qui se situe dans les plus hautes couches de la société d'Ancien Régime, caractérisées par leur richesse et leur puissance économique ${ }^{78}$. La souscription dut coûter environ 160 livres $^{79}$. Elle constituait un soutien indirect au maintien de la mission jésuite à Pékin. Parmi les souscripteurs, on relève les noms de plusieurs ministres, Bertin, Bourgeois de Boynes, Malherbes, Turgot, Vergennes et même ceux de Choiseul et d'Aranda qui avaient joué, en France et en Espagne, un rôle décisif dans la décision de la proscription de la compagnie de Jésus. Le constat implique que les contemporains ne voyaient aucune contradiction entre le fait de juger néfaste pour des raisons religieuses et politiques l'action des Jésuites en Europe et la considération pour leurs travaux sur la Chine. Un autre enseignement intéressant de l'étude de cette liste est le nombre élevé des souscripteurs francsmaçons : 84 sur 530, soit plus de $15 \%$.

Les Mémoires concernant les Chinois et l'Histoire générale de la Chine connurent un grand succès qui servit de moteur pour créer un engouement pour des livres plus modestes. En 1782, l'éditeur Nyon l'aîné utilisa un artifice de vente pour réimprimer sous le titre Lettres d'un missionnaire à Pékin contenant diverses questions sur la Chine, pour servir de supplément aux Mémoires concernant l'histoire le volume réédité en 1770 par Dortous de Mairan de ses questions à Parrenin ${ }^{80}$. La vague apporte aussi des ouvrages illustrés. Fin 1783, le graveur Isidore-Stanislas Helman (1743-1806) met en vente, par livraisons de quatre planches, une réduction des estampes réalisées en France à la demande de l'empereur Qianlong représentant ses conquêtes de l'Asie centrale. Ces gravures, au nombre de seize, avaient été exécutées sous la direction du graveur Cochin fils (1715-1790), sur des dessins envoyés par les missionnaires de Chine en 1776, expédiés par la Compagnie des Indes ${ }^{81}$. À la demande de l'empereur, les cent tirages réalisés et les planches avaient été renvoyés en Chine, à l'exception de quelques exemplaires tirés pour la famille royale et la bibliothèque du roi. Cette rareté a donné l'idée à Helman d'en exécuter des formats réduits pour satisfaire la curiosité des amateurs. Le succès fut tel que Helman publia deux autres suites, de vingt-quatre estampes chacune, in $-4^{\circ}$, intitulées Abrégé historique des principaux traits de la vie de Confucius et Faits mémorables des empereurs de Chine. La publication de cette seconde série, divisée en quatre livraisons espacées de deux mois, débuta le 15 avril 1788. Elle illustre des épisodes de l'histoire chinoise puisés dans la traduction du

78. MiLsKy, 1977, p. 113.

79. J'effectue ce calcul en divisant le montant de 86000 livres réuni par la souscription par 530, nombre des souscripteurs. Le chiffre de 86000 livres est cité par MicHAUD, 18431858, art. « Grosier », vol. XVII, p. 602.

80. BARBIER, 1872-1879, vol. II, p. 1241, signale la supercherie en faisant remarquer que Nyon s'est contenté de changer le frontispice de l'édition originale.

81. Voir PirazZoli-T’SersteVens, 1969. 
père de Mailla. Quant à la première série, l'Abrégé historique, composée de vingt-quatre gravures, elle illustre des épisodes marquants de la vie de Confucius. À ce titre, elle nous intéresse particulièrement pour souligner à quel point Lavicomterie s'est coulé dans une mode dont il espérait sans doute qu'elle porterait son entreprise. Un premier tirage de cet Abrégé historique fut exécuté en 1786. Rapidement épuisé, il fit l'objet d'un second tirage, en 1788, l'année du pamphlet de Lavicomterie. Les gravures sont inspirées de dessins envoyés en France par Amiot à Bertin ${ }^{82}$. Le texte mis en regard des illustrations rassemble des extraits des Pensées morales de Confucius ${ }^{83}$, un ouvrage qui était paru en 1782 dans une collection dédiée au roi intitulée Les Moralistes anciens qui avait été approuvée par le garde des Sceaux. Ce texte est une nouvelle traduction du latin du Confucius sinarum philosophus de Philippe Couplet assurée par un M. Levesque.

\section{LE SCANDALE DE LA GRAVURE D'HELMANN}

La première gravure de l'Abrégé historique des principaux traits de la vie de Confucius, mis en vente par Helman, provoqua un scandale qui révèle la captation de l'image du philosophe chinois au service du rejet des fondements de la monarchie de droit divin. La gravure, inspirée par le portrait du sage figurant dans l'ouvrage de Couplet, représente Confucius assis « tel qu'il était anciennement représenté à la vénération des lettrés ». Elle est légendée du quatrain de Voltaire cité plus haut. Cette initiative de l'éditeur provoqua une réaction immédiate outragée de L'Année littéraire, le périodique lancé par Élie Fréron (1719-1776), qui le $1^{\text {er }}$ octobre 1786 avertit ses lecteurs : «Quel poison est enfermé dans cette inscription ${ }^{84}$ »

L'article traite Voltaire d' «Arétin moderne » et conclut : «O mes chers François, respectons, pratiquons, notre Sainte Religion, chérissons le Roi et la patrie, exaltons les grands modèles [...]. »

L'indignation n'est pas celle de Fréron (dont on connaît les démêlés avec Voltaire) qui était mort à cette date, mais probablement celle de l'abbé Grosier, que les héritiers de Fréron avaient supplié de prendre sa succession à la tête de L’Année littéraire.

82. Les dessins originaux envoyés à Bertin sont conservés à la réserve des estampes de la Bibliothèque nationale de France. Ils s'inspirent des Shengji tu qui datent des Ming ; voir Murray, 1997.

83. Bibliothèque nationale de France : Rés.R.2011.

84. L'Année littéraire, 2, 1786, col. 234-236. 
Si on ne peut être certain que Lavicomterie fit l'acquisition de l'Abrégé de la vie de Confucius, dont le prix n'était pas modique ${ }^{85}$, il n'est pas improbable qu'il put y avoir accès dans un cabinet de lecture, ou du moins, qu'il en eut connaissance par l'écho de L'Année littéraire ou par l'annonce de sa mise en vente dans le Journal de Paris. Tous les journaux du temps insérèrent des encarts sur ces publications sur la Chine. La gravure de Confucius par Helman circula sans doute largement dans les années 1786-1788. Sans les vers controversés de Voltaire, les éditeurs des Mémoires concernant les Chinois l'ont faite figurer en tête du douzième volume publié en 1786. La récurrence de la représentation de Confucius dans ces années et le rappel prégnant des productions jésuites entretenaient une mode dans la galaxie des gens de lettres, dans laquelle Lavicomterie s'engouffra pour rallier des lecteurs. Sans que les censeurs aient semblé en prendre conscience ${ }^{86}$, l'assimilation entre Confucius et Voltaire est suggérée dans le texte qui accompagne le portrait du philosophe dans l'Abrégé mis en vente par Helman :

« [...] en butte aux persécutions des Courtisans qui parvinrent enfin à corrompre leur Maître, il fut réduit à s'éloigner en pleurant, du Pays dont il avait fait le bonheur. Il parcourut différens États, toujours égal à lui-même dans l'adversité comme dans la prospérité. Il mourut à l'âge de 73 ans. On a conservé ses dernières paroles. "Les Rois dit-il n'observent pas ce que j'enseigne ; aucun d'eux ne suit mes principes ; il ne me reste plus qu'à mourir.” Il reçut après sa mort des honneurs qui n'ont jamais été rendus à aucun homme à moins que la superstition ne l'ait placé parmi les Dieux. Aujourd'hui encore tous les Sages, tous les Magistrats, tous les Lettrés se vantent d'être ses Disciples ${ }^{87}$. »

Ce texte non signé de l'Abrégé précise dûment qu'il cite ici la collection dédiée au roi des Moralistes anciens. L'allusion, mode opératoire du contournement de la censure, tient le rôle déclencheur de captation d'image sur lequel Lavicomterie a joué. L'évocation à mots couverts de l'exil à Cirey, des pérégrinations de Voltaire en Prusse et dans les autres pays européens, des scènes auxquelles avaient donné lieu ses funérailles, durent paraître suffisamment transparentes à tous ceux décidés à comprendre.

Ajoutons qu'en 1788, l'annonce d'une publication d'un manuscrit jésuite inédit n'était pas totalement invraisemblable. Les pères Bourgeois et Amiot étaient encore en vie et auraient pu, pourquoi pas, envoyer en Europe une ancienne

85. Prix : 12 livres ; 13 livres 10 sols pour un exemplaire broché, Journal de Paris, 9 oct. 1786.

86. Le volume II de la collection des Moralistes anciens porte en date du 11 février 1781 l'approbation du garde des Sceaux Guyot : «Je crois qu'on peut permettre l'impression de cette partie intéressante de la morale des Anciens, dont la collection devient sous la plume d'Ecrivains célèbres, une nouvelle richesse pour la République des Lettres. » Citation prélevée sur l'exemplaire de la Bibliothèque nationale de France : $16^{\circ}$ R.6626 (2).

87. Abrégé, légende de la planche 1, Bibliothèque nationale de France : $\mathrm{O} 2$ n.624 (2). 
traduction de Parrenin qu'ils auraient retrouvée dans les archives de la mission. Le père Amiot mourra dans la nuit du 8 au 9 octobre 1793 d'une attaque d'apoplexie, vingt-quatre heures après que lui soit parvenue l'annonce de la décapitation de Louis XVI.

\section{LE PAMPHLET}

Le Code de la nature est un opuscule, du type de ces « petits livres portatifs à trente sous qui sont à craindre », du point de vue de la censure, selon le mot de Voltaire ${ }^{88}$. Après l'Avertissement, fictivement attribué à Parrenin, il se compose de deux parties rimées (appelées « chants » par Coqueley) censées avoir été composées par Confucius, suivies de commentaires censés avoir été composés par Parrenin. Le premier chant s'intitule De la morale universelle 89 et son commentaire Contre Hobbes, et contre ceux qui ont dit que l'homme naissait méchant ${ }^{90}$. Le second chant s'intitule Des supplices et de la peine de mort $^{91}$. Il est accompagné de trois commentaires dont le premier s'intitule Entretien d'un philosophe et d'un fakir ${ }^{92}$, le second reprend le titre Des supplices et de la peine de mort $^{93}$, le troisième Entretien du philosophe Criton, disciple de Socrate, et de Barbarakinquorix, l'un des Cinq-Cents d'Athènes ${ }^{94}$.

Les quatre premiers vers entrent en matière en rimant le principe de la bonté originelle de l'homme :

«L'homme naît juste et bon ; en vain Hobe en murmure.

Les Prêtres*, les Tyrans, ont perdu la nature

Triste calculateur de ses égaremens

Interroge, avec moi, son instinct \& ses sens ${ }^{95}$. »

L'astérisque, censé avoir été placé par le père Parrenin, précise : «Les Prêtres fanatiques qui ont déshonoré leur sacré caractère. » Ce quatrain peut être rapproché de la diatribe de Morelly :

«Écoutez-les tous [les Moralistes et les Législateurs, Bacon, Hobbes, Locke, Pope, Montesquieu], ils vous posent pour principe incontestable et pour base de tous leurs systèmes, cette importante proposition "l'homme naît vicieux et

88. VoltaiRe, 1968-, Lettre à d'Alembert du 5 avril 1766, D 13235.

89. [LAVICOMTERIE], 1788, p. 1-13.

90. [LAVICOMTERIE], 1788, p. 25-77.

91. [LAVICOMTERIE], 1788, p. 14-24.

92. [LAVICOMTERIE], 1788, p. 78-84.

93. [LAVICOMTERIE], 1788, p. 85-111.

94. [LAVICOMTERIE], 1788, p. 112-125.

95. [LAVICOMTERIE], 1788, p. 1. 
méchant". Aucun ne s'est avisé qu'on pouvait proposer et résoudre cet excellent Problême : Trouver une situation dans laquelle il soit presqu'impossible que l'homme soit dépravé, ou méchant, ou du moins, minima de malis ${ }^{96}$. »

Cible visée par les deux pamphlétaires, le philosophe anglais Thomas Hobbes (1588-1679), auteur du Léviathan et du De homine parus en 1651 et 1658, incarne la vision pessimiste de l'état de nature qu'il n'envisage que nécessairement chaotique, entraînant l'homme sous l'empire du plaisir et de la souffrance vers la guerre et une vie solitaire, brutale et courte. Hobbes qui vécut dans le temps des guerres civiles du XVII ${ }^{\mathrm{e}}$ siècle s'était déclaré pour l'égoïsme dans le domaine de la morale et pour le despotisme en politique. Son œuvre, perçue comme une négation de la liberté individuelle, faisait l'objet d'une intense attention. D'Holbach en avait traduit des morceaux. Morelly fait voix au courant radicalement opposé pour qui l'amour-propre est un mobile général suffisant pour pousser l'homme vers le bien, dans la mesure où l'instinct de conservation lui dicte la nécessité de la réciprocité : «Tu veux être heureux, sois bienfaisant. Sans t'embarrasser d'abord de qui tu tiens l'être, apprens que tu ne peux en jouir sans être bienfaisant. Veux-tu t'élever à la connoissance de ton Auteur? Sois bienfaisant ${ }^{97}$. »

Lavicomterie glose la même idée :

« N'oublions jamais que l'Univers est fait pour en jouir en commun ; Isole-toi, si tu le veux, mais souffre que je vive en société, \& laisse moi jouir du bonheur en le rendant à mes frères. Ou plutôt, sors de ton trou, et travaille à ton bonheur en faisant celui d'autrui, et ne t'amuse plus à deviner des logogriphes ; ou du moins, si tu ne veux pas être inutile, que ta folie ne soit point atroce et nuisible ${ }^{98}$. »

Ces paroles sont mises dans la bouche de Confucius dans le premier chant. L'originalité de Lavicomterie est d'agréger, sur la base d'une opposition à l'idée de la méchanceté de l'homme ancrée dans la vision de la chute par le péché originel, la définition d'un confucianisme issu de la loi naturelle telle qu'il l'interpréta à partir de ce qu'il savait des écrits des Jésuites. La morale confucéenne, fondée sur un pari sur l'homme, vient ainsi donner une impulsion à une recherche de la liberté à la portée de tous et le choix d'un destin librement consenti. L'invocation du philosophe chinois, dont la pensée est confondue avec celle de Mencius (v. 380-v. 289 avant J.-C.), qui beaucoup plus que son prédécesseur s'identifie avec l'idée de la bonté fondamentale de la nature humaine, montre qu'aussi floues que soient les leçons retenues de la philosophie chinoise, leur attrait semble avoir résidé dans une continuité spirituelle ignorant

96. Morelly, 1755, p. 14.

97. Morelly, 1755, p. 158.

98. [LAVICOMTERIE], 1788, p. 65. 
la notion de déchéance. Le Confucius de Lavicomterie parle d'un « pacte éternel : jouis et fais jouir ${ }^{99} »$, perverti par des institutions sociales cruelles et inutiles.

Le second chant est construit autour de la révolte face aux spectacles des châtiments publics et l'inanité de leur valeur exemplaire :

«Chaque jour l'homme en vain outrage la nature

Les gibets, les bûchers, la roue \& la torture,

Monumens fugitifs de trop de cruauté,

Dont s'éloigne, en pleurant, le sage épouvanté,

N'arrêtent pas la main par le crime enhardie.

Cet horrible moment frappe, passe et s'oublie.

Ne peut-on, sans la mort, punir les criminels !

Faut-il être, comme eux, injustes et cruels !

Ah ! S'il est aussi vrai que l'homme soit l'image

Du Dieu dont il dépend, comme il en est l'ouvrage,

Osez-vous, sans frémir, l'envoyer à la mort,

Frapper le simulacre, \& le Dieu dont il sort ${ }^{100}$ ! »

À l'usage des crédules qui eussent pu croire à l'authenticité du poème, les injustices judiciaires sont identifiées : Urbain Grandier, François Auguste de Thou, Jean Calas et Thomas-Arthur de Lally de Tolendal ${ }^{101}$, cas historiques dont Confucius aurait difficilement pu épouser la cause. Dans le commentaire mis dans la bouche d'un Barbaraquintorix qui incarne l'arbitraire du pouvoir judiciaire, c'est l'affaire Calas qui fait l'objet des allusions les plus transparentes :

«Celui que j'ai fait expirer sur la roue, étoit un monstre faible de corps, usé par les années et les travaux ; mais d'une tête forte, \& d'une ame atroce. Un soir, oubliant la tendresse paternelle qu'il avait toujours montrée, il pendit lui seul, à soixante-huit ans, son fils, qui n'en avait que vingt-deux [...]. Nous n'avions pas, à la vérité, un témoin de visu, \& les scélérats ont attesté le Ciel de leur innocence jusqu' au dernier soupir ; mais nous avions cent demi-preuves, qui jointes ensemble, faisoient un corps complet ${ }^{102}$. »

Pour marquer quelque distance avec le texte, Lavicomterie a inséré une note où il s'est essayé à imiter l'ironie de son maître Voltaire, quoiqu'on puisse juger qu'elle ne soit pas aussi réussie que l'originale: «Quelques Savans versés dans l'Antiquité, prétendent que la torture n'a été inventée que plus de trois mille ans après par des voleurs de grands chemins; je suis entièrement de leur avis ; \& ce passage nous parait visiblement altéré, ainsi que plusieurs autres. »

99. [LAVICOMTERIE], 1788 , p. 7.

100. [LAVICOMTERIE], 1788, p. 17.

101. [LAVICOMTERIE], 1788, p. 23.

102. [LAVICOMTERIE], 1788, p. 117-118. 
Lavicomterie avait une trentaine d'années lorsque Jean Calas fut roué vif en 1762 et nul doute qu'il dut suivre les plaidoyers pathétiques de Voltaire. Ces combats avaient rencontré des succès auprès d'une opinion qui se mobilisait contre la violence institutionalisée. Le Dei delitti et delle peine de Cesare Beccaria (1738-1794) publié en 1764 avait été traduit deux ans plus tard par l'abbé André Morellet (1727-1819). En 1780 et 1788, plusieurs édits limitèrent l'emploi de la torture.

Dans le constat que la loi de Dieu ne réprime pas la violence mais qu'une loi humaine peut l'adoucir, les écrits des Jésuites sur la Chine avaient alimenté le débat sur le droit naturel en fournissant sur la Chine l'information de la modération du législateur. Dans la Description de la Chine, Du Halde avait affirmé non seulement que l'attention la plus scrupuleuse était apportée dans les condamnations à mort ${ }^{103}$ mais avancé une préoccupation d'appliquer l'égalité devant la loi. «Ainsi à la Chine on accorde à l'homme le plus vil \& le plus miséreux, ce qui ne s'accorde en Europe comme un grand privilège, qu'aux personnes les plus distinguées, c'est-à-dire, le droit de n'être jugé \& condamné que par toutes les Chambres du Parlement assemblées en corps ${ }^{104}$. »

Premier état européen à le faire, la Toscane avait aboli la peine de mort en 1786.

La fantaisie imaginative de Lavicomterie truffe son pamphlet d'invraisemblances qui amènent la présence aux côtés de Confucius d'un fakir qui incarne la rapacité des religieux. Membre d'un institut religieux proscrit, Parrenin le tance pour déplorer les dîmes : «Le bon Fakir se trompe. C'est la $10^{\text {ème }}$ partie ; ce qui revient à la $5^{\text {ème }}$; il est vrai, les frais de culture réduits ; et son raisonnement subsiste, comme disent les Doctes. »

Dans la verve de Lavicomterie, une complicité de proscrits s'établit entre Confucius et Parrenin qui justifie la méfiance envers les facultés qui condamnent et les docteurs qui interprètent les dogmes au service des pouvoirs. Lavicomterie passe au moulin de la dérision petites et grandes théories, sur l'origine commune des Égyptiens et des Chinois ou sur la chronologie du monde, toujours au plus près des moqueries déjà lancées par Voltaire :

«[...] nous savons, de science certaine, que tout le monde fut noyé l'an de grace 1656 de la création, excepté Noë \& sa famille, comme il apert par la Sainte Ecriture.

«Certes Noé envoya sa famille voyager loin ; son petit-fils Menès en Egypte, son autre petit-fils à la Chine, je ne sais quel autre petit-fils en Suède, et un cadet en Espagne. Les voyages formaient alors les jeunes gens bien mieux qu' aujourd'hui. »

103. Du HalDE, 1735, p. 136 et 1736, p. 161.

104. Du Halde, 1735, p. 137 et 1736, p. 161. 
En s'appuyant sur une triple falsification - détournement des écrits de Confucius, du père Parrenin et de Diderot qui ne trompa pas, dans les deux premiers cas, les contemporains attentifs -, le pastiche de Lavicomterie attire l'attention sur la participation de l'image de la Chine au processus de rejet de la monarchie de droit divin. Au temps de La Mothe Le Vayer, l'annexion de Confucius au panthéon des Sages crée un scandale officialisé en 1700 par la condamnation de la Faculté de théologie de la Sorbonne. Sous Louis XVI, la parution d'une collection regroupant les Moralistes anciens ne suscite plus de réactions, mais l'objet du scandale se déplace avec l'identification de Confucius à Voltaire.

En caricaturant Confucius en simple objet des Jésuites - « leur » Keumfucum -, Pascal, ignorant délibérément son rôle structurel dans la pensée chinoise, en avait fait le repoussoir d'une contestation doctrinale bientôt qualifiée d'athéisme. Dans l'esprit des Jésuites du XVI ${ }^{\mathrm{e}}$ et du XVII ${ }^{\mathrm{e}}$ siècle, la loi naturelle était une étape précédant la révélation qui s'inscrivait dans une vision linéaire de l'évolution du monde. Sous l'effet des Lumières, la loi naturelle devint une sublimation des querelles de chapelle, un dépassement raisonné des discordes religieuses. En louant par ailleurs le bon état des institutions chinoises et en exagérant le consensus pacifique du fonctionnement social, les Jésuites laissèrent s'installer la possibilité d'une identification de Confucius avec une conduite des affaires politiques indépendantes de la sanction du droit divin. La condamnation romaine des rites chinois suivie de la suppression de la Compagnie ratifièrent cette identification. Cette évolution semble s'être faite indépendamment du contenu des traductions de Confucius exécutées par les Jésuites, dont les contemporains ne retinrent que des formules vagues de bon sens, de confiance en la nature humaine, de refus de l'intolérance et de la superstition. Une version épurée du christianisme susceptible d'universaliser les leçons de l'humanisme. En distillant tous ces ingrédients, Lavicomterie fut sans doute représentatif des contradictions et des attentes intellectuelles et morales à la veille de la Révolution. Comme les Persans de Montesquieu, «le » philosophe chinois commenté par «le » jésuite pose le regard le plus acide sur les tares de l'Ancien Régime. Penchés sur le chaudron où bouillonnent les idées nouvelles, Confucius, Parrenin et Diderot fustigent l'injustice. C'est le mérite de Lavicomterie de nous introduire auprès de ce trio improbable qui hantait peu ou prou l'esprit des clients du libraire Leroy.

Isabelle LANDRY-DERON*

(avril 2001).

\footnotetext{
* L'auteur remercie Jean-Claude Perrot pour ses suggestions èt remarques précieusés sur les lumières utopiques.
} 


\section{LISTE DES RÉFÉRENCES}

Abrégé historique des principaux traits de la vie de Confucius, célèbre philosophe chinois, orné de 24 estampes in- $4^{\circ}$, gravées par Helman, d'après les dessins originaux de la Chine envoyés à Paris par le P. Amiot, missionnaire à Pékin et tirées du cabinet de M. Bertin, ministre et ancien secrétaire d'État, 1786, Paris.

ARnauld (Antoine), 1701, De la nécessité de la foi en Jésus-Christ, où l'on examine si les payens \& les philosophes qui ont eu la connoissance d'un Dieu \& qui ont moralement bien vécu, ont pû être sauvez sans avoir la foy en Jésus-Christ, Paris, C. Osmont, 2 vol.

BACZKo (Bronislav), 1978, Lumières de l'utopie, Paris, Payot.

BARBIER (Antoine A.), 1872-1879, Dictionnaire des ouvrages anonymes, Paris, 4 vol.

BERNIER (François), 1688, Copie des étrennes envoyées à Madame de la Sablière, Montpellier.

BruAnd (Yves) et HEBERT (Michèle), 1970, Inventaire du fonds français des graveurs du XVIII siècle, Paris, Bibliothèque nationale.

CASTAN (Nicole), 1980, Justice et répression en Languedoc à l'époque des Lumières, Paris, Flammarion.

Catalogue des livres de feu M. Dortous de Mairan [...] dont la vente commencera lundi 29 juillet 1771, 1771, Paris, Vve Barrois et fils.

Cheng (Anne), 1981, Entretiens de Confucius, Paris, Seuil.

Collani (Claudia von), 1990, «Philippe Couplet's attitude towards the Chinese in Confucius sinarum philosophus », in HeYndRICKX (Jeroom), éd., Philippe Couplet, the man who brought China to Europe, Nettetal, Steyler Verlag (Monumenta Serica monograph series, 22).

COUPLET (Philippe), 1687, Confucius sinarum philosophus sive scientia sinensis latine exposita, studio et opera Prosperi Intorcetta, Christiani Herdtricht, Francisci Rougemont, Philippi Couplet, adjecta est tabula chronologica sinicae monarchiae ab hujus exodio ad haec usque tempora et tabula genealogica, Paris, D. Horthemels.

DAVy (Jacques, S. J.), 1950, « La condamnation en Sorbonne des Nouveaux Mémoires sur la Chine du P. Le Comte. Les débuts de l'affaire », Recherches de science religieuse, vol. XXXVII, p. 366-397.

Dehergne (Joseph, S. J.), 1943, « Un grand Français : Dominique Parrenin 1665-1741 », Revue nationale chinoise, sept., p. 45-51.

Dehergne (J., S. J.), 1965, Les Deux Chinois de Bertin, thèse de $3^{\mathrm{e}}$ cycle, Paris, Sorbonne.

Dehergne (J., S. J.), 1973, Répertoire des jésuites de Chine de 1552 à 1800, Rome/ Paris, Institutum historicum S.I./Letouzey \& Ané.

Dehergne (J., S. J.), 1983, « Une grande collection : "Mémoires concernant les Chinois" (1776-1814) », Bulletin de l'École française d'Extrême-Orient, 72, p. 267-294. 
Demoment (Auguste, S. J.), 1962-1963, «En Chine au XVIII ${ }^{\mathrm{e}}$ siècle. Le père Dominique Parrenin 1665-1741 », in Procès-verbaux et mémoires de l'Académie des sciences, belles-lettres et arts de Besançon, 175, p. 225-243.

DocKes (Nicole), 1985, «Un ordre naturel communautaire du XVIII ${ }^{\mathrm{e}}$ siècle : Morelly », in KLOTz (Gérard), éd., Ordre, nature, propriété, Lyon, Presses de l'université de Lyon, p. 63-118.

Du HALDE (Jean-Baptiste, S. J.), 1735, Description géographique, historique, chronologique, politique et physique de l'empire de la Chine et de la Tartarie chinoise,

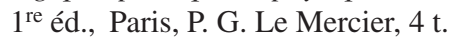

Du Halde (J.-B., S. J.), 1736, Description géographique, historique, chronologique, politique et physique de l'empire de la Chine et de la Tartarie chinoise, rééd., La Haye, H. Scheurleer, 4 t.

Dupront (Alphonse), 1996, Qu'est-ce que les Lumières ?, Paris, Gallimard (Folio).

EHRARD (Jean) et Roger (Jacques), 1965, « Deux périodiques français du XVIII ${ }^{\mathrm{e}}$ siècle. Le Journal des savants et les Mémoires de Trévoux, essai d'une étude quantitative », in Livre et société dans la France du XVIII siècle, Paris, Mouton.

Éloge de la ville de Moukden et de ses environs, poëme composé par Kien-Long, empereur de la Chine et de la Tartarie, actuellement régnant. Accompagné de notes curieuses sur la géographie, sur l'histoire naturelle de la Tartarie orientale, \& sur les anciens usages des Chinois ; composées par les éditeurs chinois et tartares. On y a joint une Pièce de vers sur le thé, composé par le même empereur. Traduit en françois par le P. Amiot, missionnaire à Péking ; et publié par Deguignes, 1770, Paris, N. M. Tilliard.

Étiemble (René), 1966, Les Jésuites en Chine. La Querelle des rites, 1552-1773, Paris, Julliard (Archives).

ÉtIEMBLE (R.), 1988-1989, L'Europe chinoise, 1. De l'empire romain à Leibniz; ;. De la sinophilie à la sinophobie, Paris, Gallimard (Bibliothèque des idées), 2 vol.

Faits mémorables des empereurs de la Chine tirés des annales chinoises, dédiés à Madame, Louise-Marie Adélaïde de Savoie, comtesse de Provence, 1788, Paris, 24 estampes in- $4^{\circ}$.

FÉNELON (François DE SALIGNAC DE LA Mothe), 1970, Euvres complètes, Paris, Gallimard (Bibliothèque de la Pléiade).

FOURMONT (Étienne), 1742, Linguae sinarum mandarinicae hieroglyphicae grammatica duplex, latine, \& cum characteribus sinensium. Item sinicorum regiae bibliothecae librorum catalogus, Paris, Joseph Bullot.

GaubIL (Antoine, S. J.), 1770, Le Chou-King, un des livres sacrés des Chinois. Ouvrage recueilli par Confucius, traduit et enrichi de notes par feu le P. Gaubil, revu et corrigé sur le texte par M. de Guignes, Paris, N. M. Tilliard.

Gaubil (A., S. J.), 1970, Correspondance de Pékin, éd. Renée Simon, Genève, Droz.

GHERARDINI (Gio.,), 1700, Relation du voyage fait à la Chine sur le vaisseau l'Amphitrite en l'année 1698, par le sieur Gio. Gherardini, peintre italien, Paris.

Giboury (Jacques-Philippe), 1989, Dictionnaire des régicides, Paris, Perrin.

GILlisPIE (Charles Couston), éd., 1981, Dictionary of scientific biography, New York, Charles Scribner's sons, 16 vol.

GIRARD (Pascale), 2000, Les Religieux occidentaux en Chine à l'époque moderne, Lisbonne/Paris, Centre culturel Calouste Gulbenkian. 
Gonzalez De Mendoza (Juan, augustin), 1588, Histoire du grand royaume de la Chine, $1^{\text {re }}$ éd., Historia de las cosas mas notables, ritos y costumbres del gran reyno de la China, 1585, Rome, ici Paris.

GRENTE (Georges), 1996, Dictionnaire des lettres françaises, 2. Le dix-huitième siècle, éd. révisée et mise à jour sous la direction de François MourEaU, Paris, Fayard, 2 vol.

GRIMM (Friedrich-Melchior), 1877-1882, Correspondance littéraire, Paris, 16 vol.

Grover (Yvonne), 1980, «La correspondance scientifique du P. Parrenin (16651741)», Actes du II colloque international de Sinologie de Chantilly, Paris, Les Belles Lettres, p. 83-99.

Guignes (Joseph de ou Deguignes), 1759, Mémoire dans lequel on prouve que les Chinois sont une colonie égyptienne, Paris.

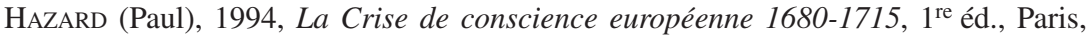
1961, ici Paris, Fayard (Livre de poche).

HOËFER (Ferdinand), 1969, Nouvelle biographie générale, $1^{\text {re }}$ éd., Paris, 1848, ici Copenhague, Rosenkilde et Bagger, 46 vol.

Hsia (Florence C.), 1999, « Some observations on the Observations. The decline of the French Jesuit scientific mission in China », Revue de synthèse, $4^{\mathrm{e}}$ sér., 2-3, avr.sept., p. 305-333.

INTORCETTA (Prosper, S. J.), 1672, Sinarum scientia politico-moralis, sive scientiae sinicae liber, inter Confuci libros secundus, a Prospero Intorcetta, e sinensi lingua in latinem versa, trad. franç., 1673, dans la collection de voyages de Melchisédech THÉVENOT, ici Paris.

L'Année littéraire, 1754-1790, Genève, Slatkine reprints, ici rééd., 1966.

La Morale de Confucius philosophe de la Chine, s. d., À Amsterdam, chez P. Savouret, attribué au Président Cousin par Barbier, 1872-1879, vol. III, p. 351.

La Morale pratique des Jésuites où l'on représente leur conduite dans la Chine, dans le Japon et dans l'Amérique, \& dans l'Éthiopie, [par Antoine ARNAULD \& SébastienJoseph Du Cambout de Ponchâteau], 1669-1695, Cologne-Amsterdam, 8 vol.

La Mothe Le Vayer (François de), 1642, De la vertu des payens, Paris, François Torga.

LANDRY-DERON (Isabelle), 1998, «L'ombre portée par l'ouvrage de Du Halde sur les premiers sinologues non missionnaires », in CARTIER (Michel), éd., La Chine entre amour et haine, Actes du VIII ${ }^{e}$ colloque de Sinologie de Chantilly, Paris, Desclée de Brouwer, p. 33-41.

LANDRY-DERON (I.), 2001, «Les mathématiciens envoyés en Chine par Louis XIV en $1685 »$, Archive for History of Exact Sciences, 55, p. 423-463.

LANDry-Deron (I.), 2002, La Preuve par la Chine. La « Description » de J.-B. Du Halde, jésuite, 1735, Paris, Éditions de l'École des hautes études en sciences sociales.

LAVICOMTERIE (Louis), 1782, Éloge de Voltaire, Paris.

[LAVicomterie (L.)], 1788, Le Code de la nature, poëme de Confucius, traduit \& commenté par le père Parennin, À Londres, et se trouve à Paris, Leroy, in- $8^{\circ}$, Bibliothèque nationale de France : Ya 559.

LAVicomterie (L.), [1789], La Liberté, ode avec des notes, s. 1. n. d.

[LAVicomterie (L.)], 1790, Du peuple et des rois, Paris, Chez les marchands de nouveautés.

LaVicomterie (L.), 1791a, Les Droits du peuple sur l'Assemblée nationale, Paris, Paquet. 
Lavicomterie (L.), 1791b, Les Crimes des rois de France depuis Clovis jusqu'à Louis XVI, Paris, Petit.

Lavicomterie (L.), 1792a, Les Crimes des papes depuis Saint Pierre jusqu'à Pie VI, Paris, Au bureau des révolutions de Paris.

Lavicomterie (L.), 1792b, La République sans impôt, Paris, Chez les directeurs du Cercle social.

[LAVICOMTERIE (L.)], 1793, Les Crimes des empereurs d'Allemagne depuis Lothaire ${ }^{\text {er }}$ jusqu'à Léopold II, Paris, Au bureau des révolutions de Paris.

[LAVICOMTERIE (L.)], 1794, Les Crimes des empereurs Turcs depuis Osman I er jusqu'à Sélim IV, Paris.

Lavicomterie (L.), 1794, Essai de morale calculée, imprimé par la Convention, Paris.

LeComte (Louis), 1990, Un jésuite à Pékin. Nouveaux mémoires sur l'état présent de la Chine 1687-1692, 1re éd., Paris, 1696, ici texte établi, annoté et présenté par Frédérique Touboul-Bouyeure, Paris, Phébus.

Le Comte (Louis), 1700, Lettre du R. P. Louis Le Comte, à Mgr le duc du Maine sur les cérémonies de la Chine, s.l.

Le GobIEn (Charles, S. J.), 1698, Histoire de l'édit de l'empereur de la Chine en faveur de la religion chrétienne avec un éclaircissement sur les honneurs que les Chinois rendent à Confucius \& aux morts, Paris, J. Anisson.

LEITES (E.), 1980, « Confucianism in eighteenth century England. Natural morality and social reform », in Actes du II colloque international de Sinologie de Chantilly, Paris, Les Belles Lettres, p. 65-81.

Lettre sur la morale de Confucius, par l'abbé S. F. [Simon Foucher], 23 janv. 1688, Paris, D. Horthemels.

Lettres édifiantes et curieuses (L.E.C.), 1702-1776, I-XXXIV, Trévoux-Paris, Nicolas Le Clerc.

LÉvy (André), 1994, Confucius. Entretiens avec ses disciples, Paris, Flammarion.

LICHTENBERGER (André), 1895, Le Socialisme au XVIII siècle. Étude sur les idées socialistes dans les écrivains français du XVIII siècle avant la Révolution, Paris, F. Alcan.

LunDBAEK (Knud), 1983, « Notes sur l'image du néo-confucianisme dans la littérature européenne du XVII ${ }^{\mathrm{e}}$ siècle à la fin du XIX siècle », in Actes du III colloque international de Sinologie de Chantilly, Paris, Les Belles Lettres, p. 131-175.

Mailla (Joseph de, S. J.), 1777-1785, Histoire générale de la Chine ou annales de cet empire traduites du Tong-Kian-Kang-mou, publiées par l'abbé Grosier et dirigées par M. Le Roux des Hauterayes, Paris, 13 vol.

MaIRAN (Jean-Jacques DorTous DE), 1759, Lettres de M. de Mairan au R. P. Parrenin, missionnaire de la compagnie de Jésus à Pékin, contenant diverses questions sur la Chine, Paris ; éd. aug., Paris, 1770, Imprimerie nationale. Texte republié en 1782 par l'éditeur Nyon l'aîné sous le titre fallacieux de Lettres d'un missionnaire à Pékin, contenant diverses questions sur la Chine, pour servir de supplément aux Mémoires concernant l'histoire.

Mémoires concernant l'histoire, les sciences, les arts, les mours, les usages, etc. des Chinois. Par les missionnaires de Pékin, 1776-1791, Paris, 15 vol.

MichaUd (Joseph), 1843-1858, Biographie universelle ancienne et moderne, Paris, 45 vol.

MiLSKY (Marie-Françoise), 1977, L'Intérêt pour la Chine en France au XVIII siècle, thèse de doctorat dirigée par François FuRET, Paris VII-École des hautes études en sciences sociales, 2 vol. 
MinAMIKI (George), 1985, The Chinese Rites Controversy from the beginning to modern times, Chicago, Loyola University Press.

Morelly, 1755, Code de la nature, Paris ; rééd., Paris, 1910, P. Geuthner (Collection des principaux économistes) ; rééd. préparée par Albert SoBoul, préface de Viatcheslav Petrovitch Volguine, membre de l'Académie des sciences sociales de l'URSS, Paris, 1953, Éditions sociales.

MurRAY (Julia K.), 1997, « Illustrations of the life of Confucius. Their evolution, function and significance in late Ming China », Artibus Asiae, vol. LVII, 1-2, p. 73-124.

NAVARrete (Domingo, O.P.), 1676, Tratados historicos, politicos, ethicos, y religiosos de la monarchia de China, Madrid, Impr. real.

PASCAL (Blaise), 1954, Euvres complètes, Paris, Gallimard (Bibliothèque de la Pléiade), 2 vol.

PAuw (Cornelius de), 1773, Recherches philosophiques sur les Égyptiens et les Chinois,

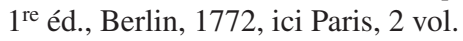

Peignot (Gabriel), 1806, Dictionnaire critique, littéraire et bibliographique des principaux livres condamnés au feu, supprimés ou censurés, Paris, 2 t. en 1 vol.

Pelliot (Paul), 1930, Le Premier Voyage de l'Amphitrite, Paris, P. Geuthner.

Pensées morales de Confucius, 1782, trad. du latin par M. LeVESQUe, Paris, Didot l'aîné (Collection des moralistes anciens).

PFISTER (Louis), 1932-1934, Notices biographiques et bibliographiques sur les jésuites de l'ancienne mission de Chine, Variétés sinologiques, 59-60, Chang-Haï, 2 vol.

Piganiol de La Force (Jean Aimar), 1765, Description historique de la ville de Paris, Paris, 8 vol.

Pirazzoli-T'Serstevens (Michèle), 1969, Gravures des conquêtes de l'empereur K'ien-Long au musée Guimet, Catalogue de l'exposition janv.-mars 1967, Paris.

QuÉRARD (Joseph-Marie), 1964, Les Supercheries littéraires dévoilées, $1^{\text {re }}$ éd., Paris, 1809, ici rééd., Paris, Maisonneuve et Larose, 3 vol.

Roche (Daniel), 1969, «Un savant et sa bibliothèque au XVIII ${ }^{\mathrm{e}}$ siècle. Les livres de Jean-Jacques Dortous de Mairan », Dix-huitième siècle, 1, p. 47-88.

RochemonteIX (Camille de, S. J.), 1915, Joseph Amiot et les derniers survivants de la mission française de Pékin (1750-1795), Paris, Picard.

RycKMans (Pierre), 1987, Les Entretiens de Confucius, Paris, Gallimard.

Sommervogel (Carlos) et De BACKer (Aloys, S. J.), 1890-1932, Bibliothèque des écrivains de la compagnie de Jésus, Bruxelles-Paris, A. Picard, 11 vol.

STREIT (Robert) et DINDINGER (Johannes), 1964, Bibliotheca missionum, chinesische

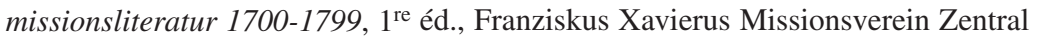
in Aachen, 1916-1939, vol. V (1929), vol. VII (1931), Rome-Fribourg-Vienne, Herder.

Touboul-Bouyeure (Frédérique), 1993, «La Chine dans le Journal des savants (1688-1765) », in Actes du Ve colloque international de Sinologie de Chantilly, San Francisco/Taipei/Paris, p. 237-255.

Trigault (Nicolas, S. J.), 1978, Histoire de l'expédition chrétienne au royaume de la Chine, $1^{\text {re }}$ éd., Augsbourg, 1615 (De christiana expeditione apud Sinas, Augusta Vindelicorum), $1^{\text {re }}$ trad. franç. Lyon, 1616, ici trad. de D. F. DE RiquebourGTrigault, Paris, Desclée de Brouwer.

Turgot (Anne Robert Jacques), 1966, EEuvres, réimp. de l'éd. de 1844, Osnabrück, Otto Zeller (Collection des principaux économistes), vol. III et IV. 
VILLEY (Pierre), 1908, Les Livres d'histoire moderne utilisés par Montaigne, contribution à l'étude des sources des Essais. Suivi d'un appendice sur les traductions françaises d'histoires anciennes utilisées par Montaigne, Paris, Hachette.

Villey (P.), 1976, Les Sources et l'évolution des Essais de Montaigne, ici rééd., Osnabrück, Otto Zeller, 2 vol.

Voltaire (François Marie Arouet, dit), 1883-1885, Euvres complètes, éd. de Louis MolAnd, Paris, Garnier, 52 vol.

Voltaire (F. M. Arouet, dit), 1968-, Correspondence and related documents, éd. Théodore Besterman, Genève-Bradburg-Oxford, Voltaire Foundation.

WeLLER (Emil), 1970, Die falschen und fingierten Druckorte. Dictionnaire des ouvrages français portant des fausses indications des lieux d'impression et des imprimeurs, rééd. Hildesheim-New York, Georg Olms, 3 vol. 